\title{
NANO/MESO/MACROPOROUS MATERIALS CHARACTERIZATION AFFECTED BY EXPERIMENTAL CONDITIONS AND FEATURES OF THE USED METHODS
}

\author{
Chuiko Institute of Surface Chemistry of National Academy of Sciences of Ukraine \\ 17 General Naumov Str., Kyiv, 03164,_Ukraine,E-mail:vlad_gunko@ukr.net
}

\begin{abstract}
The aim of this study was to analyze a set of methods: adsorption, X-ray, microscopic, cryoporometry, relaxometry, and thermoporometry used to investigate the morphological and textural characteristics of materials being in vacuum, or gaseous or liquid dispersion media, as well the interfacial phenomena basic for the used approaches. Techniques used in the studies should be divided into eight groups: (i) adsorption-desorption of lowmolecular weight probe compounds (N, Ar, etc.); (ii) adsorption or confinement of low-or high-molecular weight compounds in pores (voids) of solid particles being in liquid media; (iii) small angle X-ray scattering (SAXS) or small angle neutron scattering (SANS); (iv) quantitative analysis of images recorded using microscopic methods (TEM, SEM, AFM), etc.; (v) thermoporometry based on differential scanning calorimetry (DSC) with decreasing-increasing temperature utilizing melting thermograms; (vi) cryoporometry based on low-temperature ${ }^{l} H$ NMR spectroscopy giving the dependence of signal intensity on temperature; (vii) relaxometry based on NMR spectroscopy dealing with transverse relaxation time vs. temperature; and (viii) relaxometry based on thermally stimulated depolarization current (TSDC) measurements related to dipolar and dc relaxations. Each method could be characterized by systematic errors caused by many factors. However, the use of a set of the aforementioned methods in parallel can allow one to elucidate the reasons and level of these systematic errors that is of importance for correct characterization of the materials studied. Thus, the larger the number of methods used in parallel, the more comprehensive the morphological and textural characterization of the adsorbents.
\end{abstract}

Keywords: fumed oxides, mesoporous silicas, silica gel, activated carbons, particulate morphology, textural characteristics, systematic errors

\section{INTRODUCTION}

Experimental data on the morphological and textural characteristics could give direct (first group, e.g. microscopic methods) or indirect (second group, e.g., adsorption, SAXS, cryoporometry, relaxometry, thermoporometry) information on the characteristics and properties of materials studied. For the second group, additional treatment, using some approaches, equations, models, transformation, etc., of the data is needed to obtain expected information. For example, information on adsorption, desorption, melting, and evaporation of adsorbates is indirect for the textural characterization of adsorbents. Additionally, the results could include both random and systematic errors [1-4] reducing possibility to obtain maximum adequate characteristics of the materials from indirect information. Therefore, experimental results based on indirect information need additional tests to reduce the systematic errors, e.g., using the data based on direct information or several methods from the second group. Comparison of the treated data of several methods of both groups on the same characteristics can provide the most reliable description of the materials since the systematic errors could be more accurately estimated and eliminated. The textural characteristics of porous or disperse materials could be analyzed using nitrogen (argon, carbon dioxide or other probes) adsorption-desorption isotherms, small angle X-ray (or neutron) scattering (SAXS or SANS), cryoporometry based on nuclear magnetic resonance (NMR) spectroscopy $\left({ }^{1} \mathrm{H}\right.$ signal intensity vs. temperature), relaxometry based on NMR transverse relaxation time (T2) vs. temperature (T) or thermally stimulated depolarization current (TSDC) caused by dipolar relaxation of polar bonds and atomic groups $v s . T$, thermoporometry based on differential scanning calorimetry (DSC) and thermogravimetry (TG) vs. T. These methods can give mainly indirect information on the materials under very different conditions (low and high temperatures, vacuum or liquid dispersion media, low and high pressures, etc.) which can 
also affect the characteristics of the materials [5-16] but allow one to understand the behavior of the materials being under different conditions. The textural characterization of the materials is possible using the aforementioned methods because the behavior of adsorbates confined in pores depends on both pore sizes and temperature, as well pressure (or concentration in liquid dispersion media) $[5,6,16]$ that, however, can result in systematic errors. Note that random errors are always present in any experimental measurements [1-4] that can be estimated using a set of measurements and statistical treatment of the results, but systematic errors analyses need several methods under different conditions. There are several addition factors affecting indirect information such as (i) changes in the material characteristics due to (or during) measurements; (ii) the presence several phases (or admixtures) characterized by different dependences on the changes in measurement conditions (temperature, pressure or concentration, sample prehistory, etc.); (iii) nonuniform distribution of components in complex systems; (iv) medium effects (e.g. swelling); and (v) incorrect or inadequate models and methods used in the analyses of the experimental data $[1-4,17-28]$. As a whole, it is of importance to analyze the differences in the characteristics determined using different indirect methods taking into account the measurement conditions. These analyses give useful information on the effects of different factors in various experimental techniques that is a way to understand the reasons of the systematic errors, which could be ignored if the characterization is based only on one method. Therefore, the aim of this work was to elucidate some effects of measurement conditions and certain sources of the systematic errors in determination of the material characteristics based on indirect and direct experimental data for highly disperse fumed oxides, various porous silicas (precipitated, ordered mesoporous silicas and silica gels), porous polymers, activated carbons, and nanostructured composites.

\section{ADSORPTION}

Typically, to estimate the textural characteristics of samples degassed at increased temperature $(350-470 \mathrm{~K}$ for several hours), low-temperature $(77.4 \mathrm{~K})$ nitrogen (or argon) adsorption-desorption isotherms could be recorded using an adsorption analyzer. The specific surface area $\left(S_{\mathrm{BET}}\right)$ is calculated (using the adsorption isotherms) according to the BET method [5], which, however, has some disadvantages causing some systematic errors $[5,6,16,17]$. For example, the $S_{\text {BET }}$ value depends strongly on the pressure range used (Fig. 1) due to (i) unfinished monolayer adsorption at low $p / p_{0, \max }$ values or started multilayer adsorption at larger $p / p_{0, \max }$ values and these changes could depend on the types of both adsorbent and adsorbate; (ii) changes in an occupied area of a surface by a probe (nitrogen) molecule depending on pore sizes and structure of a solid surface (e.g. content of hydroxyls or other surface functionalities affecting orientation of adsorbed $\mathrm{N}_{2}$ molecules), etc. Additionally, the dependence is stronger for adsorbents with narrower pores (Fig. 1). Therefore, the specific surface area of adsorbents could be estimated using not only the adsorption method but also SAXS, cryoporometry, etc., which, however, can generate other systematic errors.

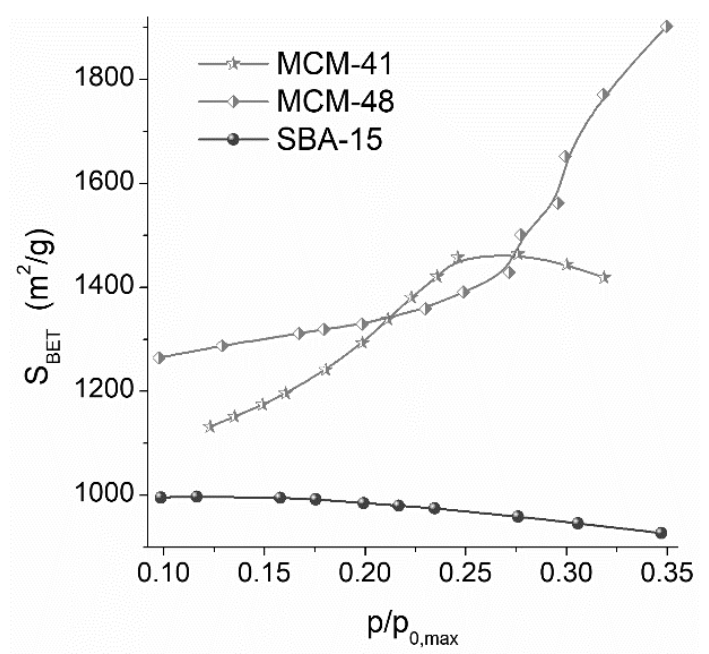

Fig. 1. The value of $S_{\mathrm{BET}}$ as a function of the maximal $p / p_{0} \quad$ value of the pressure range $\left(0.05-p / p_{0 . \max }\right)$ used upon calculation of the $S_{\mathrm{BET}}$ values for mesoporous ordered silicas MCM-41, MCM-48, and SBA-15 (some details were described elsewhere $[16,27])$

The total pore volume $\left(V_{\mathrm{p}}\right)$ could be evaluated from the nitrogen adsorption at $p / p_{0} \approx 0.98-0.99$, where $p$ and $p_{0}$ are the equilibrium and saturation pressure of nitrogen at $77.4 \mathrm{~K}$, respectively [6]. However, if an adsorbent possesses macropores, especially broad ones, the $V_{\mathrm{p}}$ value can be strongly underestimated. For example, loose powders with fumed oxides of metals or metalloid (FMO) composed of nonporous nanoparticles 
(NPNP) (3-120 $\mathrm{nm}$ in size depending on the FMO types) forming aggregates $(<1 \mu \mathrm{m}$ in size) and agglomerates of aggregates $(>1 \mu \mathrm{m})$ are characterized by a low bulk density $\rho_{\mathrm{b}}=0.04-0.15 \mathrm{~g} / \mathrm{cm}^{3}[7,8,16]$. The low bulk density corresponds to a very large empty volume in the loose powders $V_{\mathrm{em}}=1 / \rho_{\mathrm{b}}-1 / \rho_{0}$ (e.g. $24.5 \mathrm{~cm}^{3} / \mathrm{g}$ for A-300 at $\rho_{0}=2.2 \mathrm{~g} / \mathrm{cm}^{3}$ and $\rho_{\mathrm{b}}=0.04 \mathrm{~g} / \mathrm{cm}^{3}$ ), which is greater by $10-20$ times than the $V_{\mathrm{p}}$ values of FMO because nitrogen cannot completely fill macropores due to very weak interactions with distant pore walls (NPNP surface) $[5,6,16]$. Additionally, for "soft" (e.g. polymeric) adsorbents, adsorption of nitrogen fluid can lead to swelling that results in open hysteresis loops. Upon the adsorption of liquids (e.g. water) more strongly interacting with adsorbents, even solid adsorbents such as fumed silica can demonstrate slow swelling of nanoparticles $[6-9,16]$. There are the opposite effects upon strong heating of FMO because removal of intact water and surface hydroxyls leads to a decrease of NPNP sizes ( $S_{\mathrm{BET}}$ increases) and then NPNP sintering results in a decrease in the $S_{\mathrm{BET}}$ value. All these effects related to prehistory of samples can change the final results, and sometimes these results could seem unexpected.

The nitrogen adsorption-desorption isotherms could be used to compute the pore size distributions (PSD, differential $f_{\mathrm{V}}(R) \sim \mathrm{d} V_{\mathrm{p}} / \mathrm{d} R$ and $f_{\mathrm{S}}(R) \sim \mathrm{d} S / \mathrm{d} R$ ) using various approaches. These approaches could include various systematic errors caused by an inappropriate model of pores (e.g. cylindrical pores poorly modelling voids between NPNP in aggregates of FMO), inappropriate parameters of solids (e.g. parameters of carbons poorly describing polymeric adsorbents), etc. Therefore, for materials with a complex topology of pores or/and composed of several different phases (e.g. FMO and polymers or carbons, etc.), firm (Micromeritics, Quantachrome, etc.) software can give incorrect results with systematic errors. Better results could be obtained using a complex pore model with slit-shaped (S) and cylindrical (C) pores and voids (V) between spherical nanoparticles (SCV method) with the corresponding parameters for the different phases $[17,28]$. Additionally, the chemical structure of a solid surface (e.g. hydroxyls or other functionalities) can affect the interactions (and orientation, i.e., effective area of a surface occupied by a molecule) of dinitrogen or other probe molecules with a surface. The SCV method with a self-consistent regularization (SCR) procedure [17] allows one to consider the presence of several phases since the parameters of several types of surfaces (e.g. silica, alumina, titania, carbon, carbohydrate polymers, etc.) could be simultaneously used with an appropriate pore model for each component. The use of the SCR procedure gives information on contributions (weight coefficients) of different pore types and different components into the total porosity and specific surface area $[17,28]$. As a whole, the model errors remain upon the use of the SCV/SCR method because the texture of any adsorbent is not strongly ordered (pores can have very complex shape), there is a surface roughness, etc. However, the SCV/SCR method reduces the systematic errors appearing upon the application of the firm software for complex materials.

For better view of the PSD at large values of $R$, the differential PSD with respect to the pore volume $f_{\mathrm{V}}(R) \sim \mathrm{d} V / \mathrm{d} R, \int f_{\mathrm{V}}(R) \mathrm{d} R \sim V_{\mathrm{p}}$ could be recalculated to incremental PSD (IPSD) at $\Phi_{\mathrm{V}}\left(R_{i}\right)=\left(f_{\mathrm{V}}\left(R_{i+1}\right)+f_{\mathrm{V}}\left(R_{i}\right)\right)\left(R_{\mathrm{i}+1}-R_{\mathrm{i}}\right) / 2 \quad$ at $\sum \Phi_{\mathrm{V}}\left(R_{i}\right)=V_{\mathrm{p}}$ [17]. The $f_{\mathrm{V}}(R)$ and $f_{\mathrm{S}}(R)$ functions could be also used to calculate contributions of nanopores into the total pore volume and specific surface area $\left(V_{\text {nano }}\right.$ and $S_{\text {nano }}$ at radius in the range $0.35 \mathrm{~nm}<R<1 \mathrm{~nm}$ ), mesopores ( $V_{\text {meso }}$ and $S_{\text {meso }}$ at $1 \mathrm{~nm}<R<25 \mathrm{~nm}$ ), and macropores ( $V_{\text {macro }}$ and $S_{\text {macro }}$ at $25 \mathrm{~nm}<R<100 \mathrm{~nm}$ ) [17]. Clear, an incorrect PSD results in incorrect values of the textural characteristics.

The average values of the pore radii could be determined with respect to the pore volume $(X=V)$ and the specific surface area $(X=S)$, respectively, as the corresponding moments of the distribution functions

$$
<R_{X}>=\int_{R_{\min }}^{R_{\max }} R f_{X}(R) d R / \int_{R_{\min }}^{R_{\max }} f_{X}(R) d R .
$$

Additionally, $f_{\mathrm{S}}(R)$ could be used to estimate the deviation $(\Delta w)$ of the pore shape from the model using [29]

$$
\Delta w=S_{B E T} / \int_{R_{\min }}^{R_{\max }} f_{S}(R) d R-1,
$$


where $R_{\max }$ and $R_{\min }$ are the maximal and minimal pore radii, respectively. The $S_{\text {nano, }}^{*} S_{\text {meso }}^{*}$ and $S^{*}$ macro values could be corrected by multiplication by $(\Delta w+1)$ that gives $S^{*}(\Delta w+1)=S_{\text {sum }}=S_{\text {nano }}+$ $S_{\text {meso }}+S_{\text {macro }}=S_{\text {BET. }}$ The effective $w$ value $\left(w_{e f}\right)$ can be estimated with equation

$w_{e f}=\left(S_{B E T} / V_{p}\right) \int_{R_{\min }}^{R_{\max }} R f_{V}(R) d R / \int_{R_{\min }}^{R_{\max }} f_{V}(R) d R$.

However, the reliability of the $\Delta w$ values depends on the reliability of both $S_{\mathrm{BET}}$ and PSD.

The PSD functions could be also calculated using various Density Functional Theory (DFT) methods such as nonlocal DFT (NLDFT), quenched solid DFT (QSDFT), 2D-NLDFT, etc. (present in firm (Micromeritics, Quatachrome, etc.) software) or DFT version with overall equation $[17,30]$

$$
\begin{aligned}
& W(p)=v_{M}\left[\int_{\sigma_{s s} / 2}^{r_{k}(p)} \rho_{f}(R) f(R) d R+\right. \\
& \left.+\int_{r_{k}(p)}^{R_{\max }} \frac{t}{R-\sigma_{s s} / 2} \rho_{M}(R) f(R) d R\right]
\end{aligned}
$$

where $W$ is the adsorption, where $v_{\mathrm{M}}$ the liquid molar volume, $\rho_{\mathrm{f}}$ the fluid density in occupied pores, $\rho_{\mathrm{m}}$ the density of the multi-layered adsorbate in pores, $r_{\mathrm{k}}$ the radius of pores occupied at the pressure $p, \sigma_{\mathrm{ss}}$ is the collision diameter of the surface atoms. To calculate the density of a gaseous adsorbate (nitrogen) at a given pressure $p$, Bender equation [31] could be used. Transition from gas (subscript $\mathrm{g}$ ) to liquid (l) or fluid in the form of multi-layered adsorbate in pores $(\mathrm{m}) \mathrm{can}$ be linked to the corresponding fugacity $f$

$$
\begin{aligned}
& \ln \frac{f(T, \rho)}{R_{g} T \rho}=\frac{p(T, \rho)}{R_{g} T \rho}-1+ \\
& +\frac{1}{R_{g} T} \int_{0}^{\rho}\left[p(T, \rho)-R_{g} T \rho\right] \frac{d \rho}{\rho^{2}}
\end{aligned}
$$

and

$$
f_{l, m}=f_{g} \exp \left(\frac{E_{i, m}}{R T}\right),
$$

where $E$ is the interaction energy of an adsorbate molecule with the pore walls and neighboring molecules calculated with the Lennard-Jones potentials. Thus, advantages of the SCV/SCR method are the possibilities to estimate (i) contributions of several phases of complex materials into the textural characteristics; (ii) adequate PSD of complex adsorbents; (iii) both PSD and particle size distribution (PaSD); (iv) errors of the model used that could correspond to a surface roughness of adsorbents [17, 28].

To describe better the porosity of various adsorbents, an additional regularizer could be derived with maximum entropy principle [32] applied to the distribution function $f(R)$ that can be written as $N$-dimension vector ( $N$ is the number of the grid points for $f$ ) [32]. This procedure was used [27] to modify the CONTIN algorithm [33] (CONTIN/MEM- $j$ where $j$ denotes the order of $\left.\vec{p}^{j}(\vec{f})\right)$ and applied to study different silicas [27].

Any mechanical action on FMO results in certain changes in the textural characteristics of soft powders [16, 34]. However, mechanochemical activation (MCA in a ball-mill for several hours) of wetted nanosilica weakly affects the PaSD of NPNP (Fig. 2), but the structure of secondary particles (NPNP aggregates and agglomerates) strongly changes due to compaction of the powder that is well seen in changes in the PSD (Fig. 3). These changes increase with increasing MCA time that result in enhancement of the bulk density with decreasing pore volume $V_{\mathrm{p}}$ at $t_{\mathrm{MCA}}=6 \mathrm{~h}$. However, the $V_{\mathrm{p}}$ value increases at $t_{\mathrm{MCA}}=1 \mathrm{~h}$ on the initial stage of the compaction, despite the value of $V_{\mathrm{em}}$ monotonically decreases from $21.8 \mathrm{~cm}^{3} / \mathrm{g}$ (initial A-300) to $4.2 \mathrm{~cm}^{3} / \mathrm{g}\left(t_{\mathrm{MCA}}=1 \mathrm{~h}\right)$ and $2.08 \mathrm{~cm}^{3} / \mathrm{g}$ $(6 \mathrm{~h})$, but the inequality $V_{\mathrm{em}}>V_{\mathrm{p}}$ remains true. Note that the IPSD with DFT (model of voids between silica NPNP) and NLDFT (cylindrical pores in silica) quantitatively differ, but they are qualitatively similar since both show an increase in IPSD intensity with no shift of the main peaks at treatment time $t_{\mathrm{MCA}}=1 \mathrm{~h}$ and a shift of the main peaks toward smaller $R$ values and a decrease in PSD intensity at $R>10 \mathrm{~nm}$ at $t_{\mathrm{MCA}}=6 \mathrm{~h}$ (Fig. 3).

Various measurements could be carried out at low temperatures and during these experiments water or other liquids could be adsorbed and frozen at lower temperatures $T<T_{\mathrm{fr}}$ in pores of the materials studied than those in the case of free bulk liquids.

The effects of freezing of water (and other liquids, e.g. acetone) confined in pores of 
different materials can result in changes in the textural characteristics (Figs. 4 and 5) [16, 35], and these changes differ from the swelling results because the latter change the structure of the pore walls, but the former leads to increase in the pore volume and specific surface area (this is rather similar to the burn-off effects during activation of carbons). For some porous polymers, the effects are very strong (Fig. $4 a, b$ ), but for others, they could be much smaller (Fig. $4 c$ c). A similar enhancement of the porosity upon water freezing is observed for activated carbons (Fig. 5). Thus,

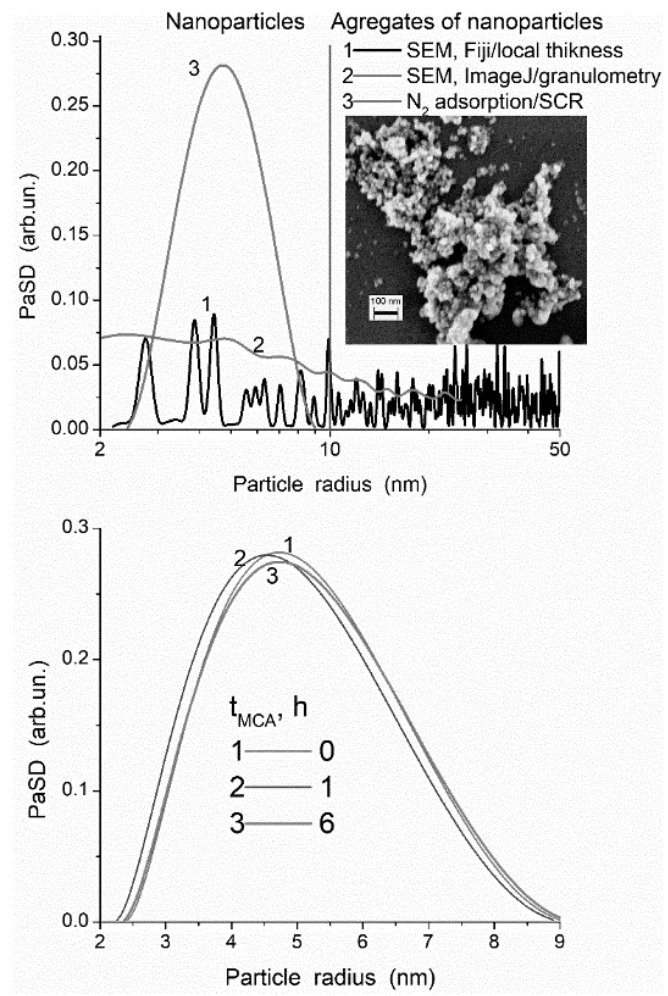

Fig. 2. PaSD for silica $(a)$ initial calculated (with Fiji/local thickness plugin, curve 1, and ImageJ/granulometry plugin, curve 2) using SEM image and nitrogen adsorption isotherm (curve 3), and (b) primary particle size distributions for silica initial $\left(S_{\mathrm{BET}}=330 \mathrm{~m}^{2} / \mathrm{g}\right)$ and MCA-treated wetted powder for $1 \mathrm{~h}\left(S_{\mathrm{BET}}=345 \mathrm{~m}^{2} / \mathrm{g}\right)$ and $6 \mathrm{~h}\left(S_{\mathrm{BET}}=332 \mathrm{~m}^{2} / \mathrm{g}\right)$ calculated using nitrogen adsorption isotherms and V/SCR method (additional details are elsewhere $[16,34])$

Thus, the use of the adsorption methods to characterize the textural features of adsorbents has not only certain advantages but also several disadvantages and systematic errors caused by (i) the effects of adsorbate (fluid) on the adsorbent texture (e.g. due to swelling or freezing); (ii) these effects depend on the types of adsorbents (chemical structure, cross-linking degree, character of interactions between adsorbent and adsorbate) and adsorbate type (e.g. structural changes in water upon freezing with increasing sizes of ice crystallites causing huge disjoining pressure up to $2000 \mathrm{~atm}$ ). This ice pressure can lead to destroying of core-shell nanoparticles (50-200 nm) of complex FMO, but smaller silica NPNP keep integrity under high pressure by ice crystallites in thick-wall stainless steel cryoreactors $[19,22]$.
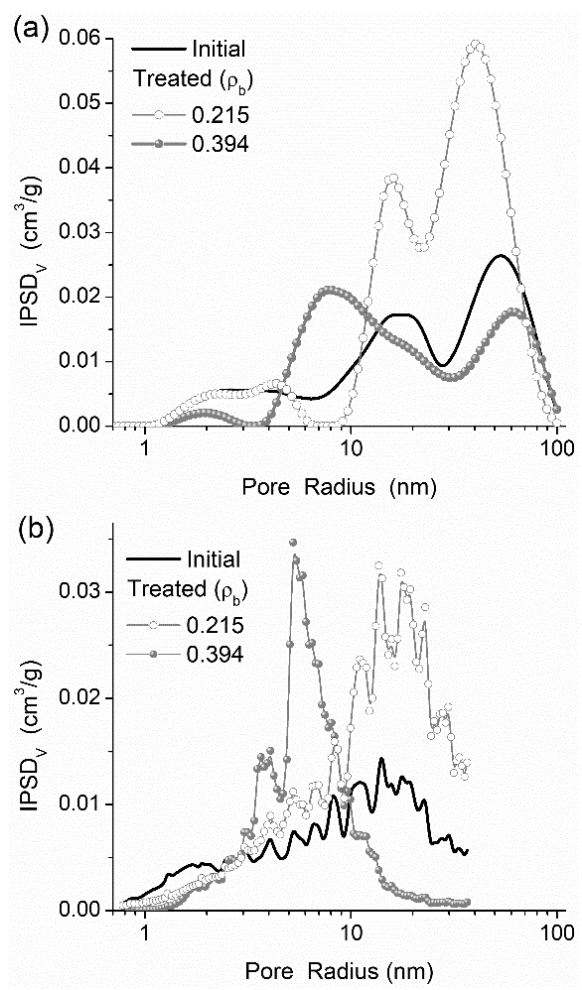

Fig. 3. IPSD for initial $\left(V_{\mathrm{p}}=0.83 \mathrm{~cm} / \mathrm{g}\right)$ and MCAtreated wetted powders for $1 \mathrm{~h}$ $\left(V_{\mathrm{p}}=1.42 \mathrm{~cm} / \mathrm{g}\right)$ and $6 \mathrm{~h}\left(V_{\mathrm{p}}=0.77 \mathrm{~cm} / \mathrm{g}\right)$ with respect to the pore volume calculated using (a) DFT/PaSD for the model of voids between spherical particles, and $(b)$ NLDFT (cylindrical pores in silica) (additional details are elsewhere [16, 34])

dependences of an occupied area and shape of a probe molecule on pore size and shape, as well on pressure; (iii) partially non-equilibrium conditions; (iv) partial accessibility of long, curved, narrow pores for adsorbate molecules; (v) as well model and equation errors. Therefore, 
parallel measurements using various methods to analyze the textural and morphological characteristics are very desirable. Among these methods the most appropriate and reliable results
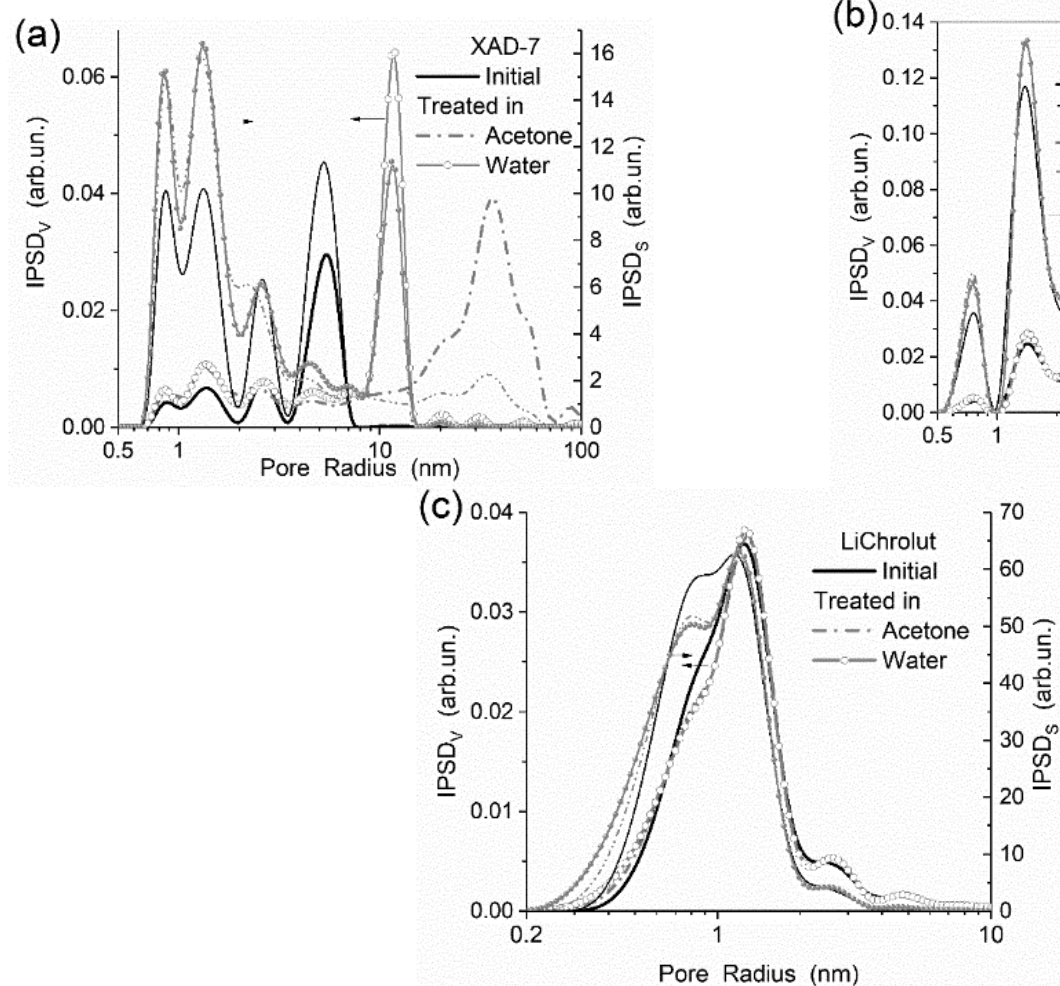

could be provided by SAXS and high-resolution TEM (HRTEM) methods. However, additional mathematic treatments of the corresponding data should be done [16-20].

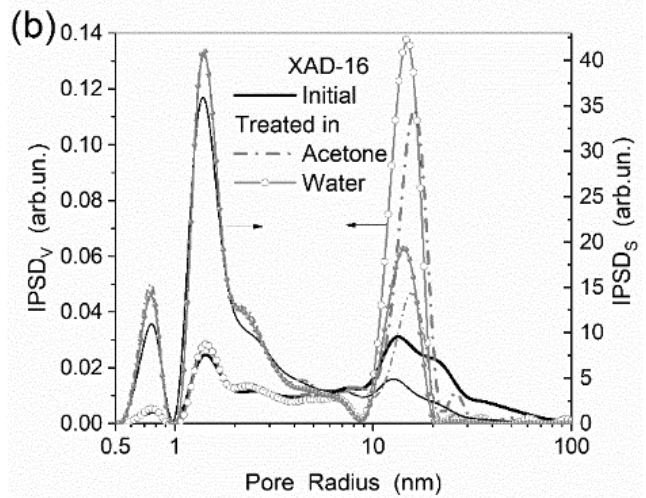




\section{SMALL-ANGLE X-RAY SCATTERING}

The differential PSD functions $f(r)$ based on the SAXS data could be calculated using Fredholm integral equation of the first kind for scattering intensity $I(q)$ [36]

$$
I(q)=C \int_{r_{\min }}^{r_{\max }} \frac{(\sin q r-q r \cos q r)^{2}}{(q r)^{2}} V(r) f(r) d r,
$$

where $C$ is a constant, $q=4 \pi \sin (\theta) / \lambda$ the scattering vector value, $\theta$ is the scattering angle, $\lambda$ is the wavelength of incident X-ray, $V(r)$ is the volume of a pore with radius $r$ (proportional to $r^{3}$ ), and $f(r) \mathrm{d} r$ represents the probability of having pores with radius $r$ to $r+d r$. The values of $r_{\min }\left(=\pi / q_{\max }\right)$ and $r_{\max }\left(=\pi / q_{\min }\right)$ correspond to lower and upper limits of the resolvable real space due to instrument resolution. This equation could

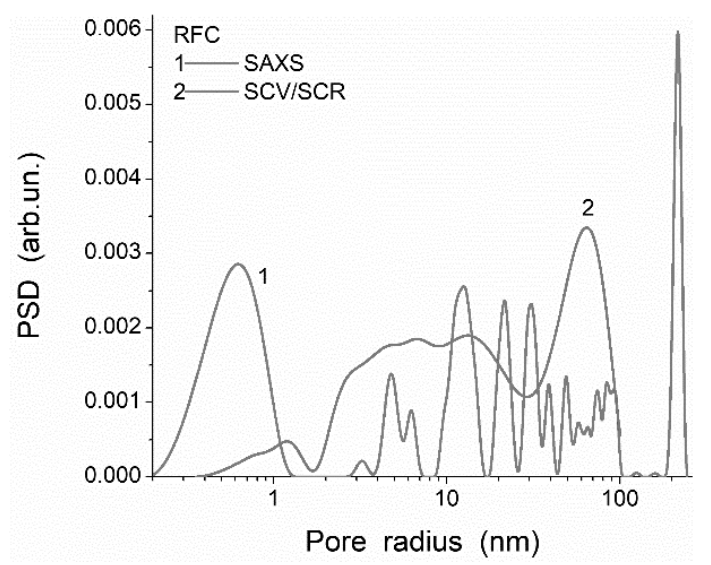

Fig. 6. Pore size distributions of a char/bentonite $(20 / 80 \mathrm{w} / \mathrm{w})$ composite $\left(S_{\mathrm{BET}}=122 \mathrm{~m}^{2} / \mathrm{g}\right.$ and $\left.S_{\mathrm{SAXS}}=262 \mathrm{~m}^{2} / \mathrm{g}\right)$, prepared upon carbonization of resorcinol-formaldehyde resin added to bentonite, calculated using SAXS and SCV/SCR methods (some details were described elsewhere [37])

To calculate the particle size distribution (PaSD) functions based on the SAXS data [39], several models of particles (e.g. spherical, cylindrical, lamellar ones and various blends of them [37]) could be used. For spherical particles, integral equation similar to Eq. (7) could be written as follows

$I(q)=C \int_{R_{\min }}^{R_{\max }} P(q, r) f(r) d r$, be solved using the CONTIN algorithm [33]. The $f(r)$ function could be converted into incremental PSD (IPSD) $\Phi\left(r_{i}\right)=\left(f\left(r_{i+1}\right)+f_{\mathrm{V}}\left(r_{i}\right)\right)\left(r_{\mathrm{i}+1}-r_{\mathrm{i}}\right) / 2$ for better view of the PSD at larger $r$ values (similar to the PSD based on the adsorption data). The main advantage of the SAXS method upon the textural characterization [16, 36-39] is that all open and closed pores could be analyzed in contrast to the adsorption methods giving the characteristics only of pores accessible for probe molecules (Figs. 6 and 7); therefore, practically always $S_{\mathrm{SAXS}}>S_{\mathrm{BET}}$ (Figs. 6-8). Comparison of the SAXS and adsorption PSD, as well the $S_{\mathrm{SAXS}}$ and $S_{\mathrm{BET}}$ values, allows one a deeper insight into the textural features of the materials studied under various conditions. Additionally, the SAXS data could be used to compute the PaSD for particles of different shapes [37].

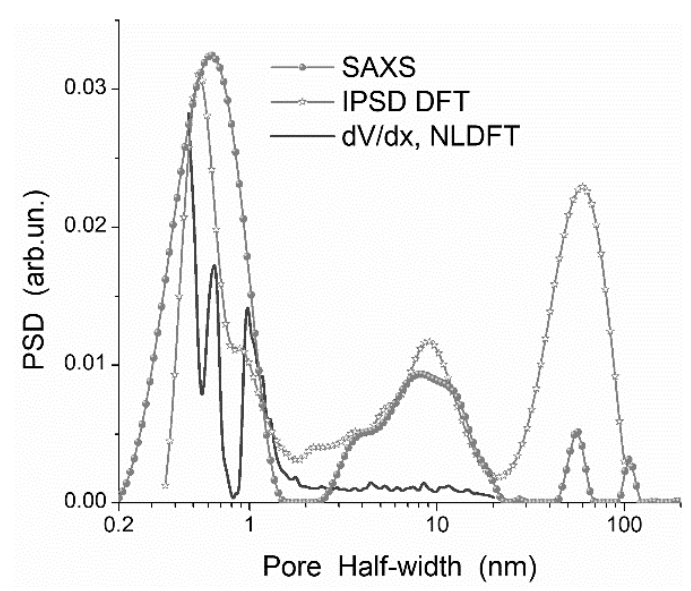

Fig. 7. Pore size distributions of activated carbon (carbonization of phenol formaldehyde resin and subsequent activation by $\mathrm{CO}_{2}$ at $1183 \mathrm{~K}$ with $60 \%$ burn-off) $\left(S_{\text {BET }}=1999 \mathrm{~m}^{2} / \mathrm{g}\right.$ and $\left.S_{\mathrm{SAXS}}=2211 \mathrm{~m}^{2} / \mathrm{g}\right)$ calculated using SAXS, DFT (Eq. (7)) and NLDFT methods (some details were described elsewhere [38])

where $C$ is a constant, $r$ is the radius of particles, $f(r)$ is the distribution function (differential PaSD), and $P(r)$ is the form factor for spherical particles [39] (the kernel of the integral equation): $P(q, r)=\left(4 \pi r^{3} / 3\right)^{2}[\Phi(q)]^{2} \quad$ where $\Phi(q, r)=\left(3 /(q r)^{3}\right)[\sin (q r)-q r \cos (q r)]$. The PaSD with respect to the volume of particles (as abundance in vol \%) could be calculated as follows abundance $(\operatorname{vol} \%)=r^{3} f(r) / \int r^{3} f(r) d r$. 
For cylindrical particles, there are two variable parameters, such as the radius $(r)$ and length $(H)$ of cylinders

$$
I(q)=C \int_{H_{\min }}^{H_{\min }} \int_{r_{\min }}^{r_{\max }} f(H) f(r) P(q, H, r) d H d r
$$

where

$$
P(q, H, r)=C V \int_{0}^{\pi / 2} \frac{2 J_{1}(q r \sin \theta)}{q r \sin \theta} \frac{\sin (0.5 q H \cos \theta)}{0.5 q H \cos \theta} \sin \theta d \theta,
$$

$J_{1}(x)$ is the first-order Bessel function, $V=\pi r^{2} H$ is the cylinder volume, and $C$ is a constant [39].

For lamellar particles [39]

$$
I(q)=C \int_{L_{\min }}^{L_{\max }} P(q, L) f(L) d L,
$$

where $L$ is the lamellar thickness, and the prefactor $\left(1 / q^{2}\right)$ is the so-called Lorentz factor required to randomize the orientation of the lamellar particle and $P(q, L)=(L / q)^{2}\left[\frac{\sin (q L / 2)}{(q L / 2)}\right]^{2}$ [39]. In the case of complex systems, several models with various blends of spherical, cylindrical and lamellar particles could be used with certain weight coefficients.

For a complex model of particles, the integral equation includes three terms [37]

$$
\begin{aligned}
& I(q)=c_{s p h} \int_{r_{\min }}^{r_{\max }}\left(\frac{4 \pi r^{3}}{3}\right)^{2}\left[\frac{3}{(q r)^{3}}(\sin (q r)-q r \cos (q r)]^{2} f(r) d r+\right. \\
& +c_{l a m} \int_{L_{\min }}^{L_{\max }}(L / q)^{2}\left[\frac{\sin (q L / 2)}{(q L / 2)}\right]^{2} f(L) d L+ \\
& +c_{c y l} \int_{H_{\min }}^{H_{\max }} f(H) \int_{r_{\min }}^{r_{\max }} \frac{\pi r^{2}}{H} f(r) \int_{0}^{\pi / 2} \sin \theta \frac{2 J_{1}(q r \sin \theta)}{q r \sin \theta} \frac{\sin (0.5 q H \cos \theta)}{0.5 q H \cos \theta} d \theta d R d H
\end{aligned}
$$

where $I(q)$ is the X-ray scattering intensity, $q=4 \pi \sin (\theta) / \lambda$ is the scattering vector value, $2 \theta$ is the scattering angle, $\lambda$ is the wavelength of incident X-ray, $R$ is the radius of particles, $H$ and $R$ are the length and radius of cylinders, $L$ is the lamellar thickness, $f(r), f(L)$, and $f(H)$ are the distribution functions, $J_{1}(x)$ is the first-order Bessel function, $c_{x}$ are the weight coefficients calculated, as well $f(x)$ functions, using a selfconsistent regularization procedure [17] to solve Eq. (12). For example, Fig. 8 shows changes in the PaSD function (calculated with Eq. (12) using the SCR procedure) upon carbonization of resorcinol-formaldehyde resin bound to bentonite particles. These changes show that particle (polymer phase) carbonization results not only in diminution of the particles (e.g. at $\mathrm{r}<7 \mathrm{~nm}$ ) but also in certain consolidation of them (at $r=8-15 \mathrm{~nm}$ and $r>30 \mathrm{~nm}$ ).

The chord size distribution, $G(h)$ as a geometrical statistic description of a multiphase medium, could be calculated from the SAXS data $[40,41]$

$$
G(h)=C \int_{0}^{\infty}\left[K-q^{4} I(q)\right] \frac{d^{2}}{d h^{2}}\left(-4 \frac{\sin q h}{q h}\right) d q,
$$

where $K$ is the Porod constant (corresponding to scattering intensity $I(q) \sim K q^{-4}$ in the Porod range).

The specific surface area from the SAXS data could be calculated (in $\mathrm{m}^{2} / \mathrm{g}$ ) using equation

$$
S_{\mathrm{SAXS}}=10^{4} \pi \phi(1-\phi) \frac{K}{Q \rho_{a}},
$$

where $\phi=\rho_{a} / \rho_{0}$ is the solid fraction of adsorbent, and $Q$ is the invariant

$$
Q=\int_{0}^{\infty} q^{2} I(q) d q
$$

The $Q$ value is sensitive to the range used on integration of Eq. (15) (since experimental $q$ values are measured between the $q_{\min }$ and $q_{\max }$ values different from 0 and $\infty$ ). Therefore, the invariant value $Q$ could be calculated using equation [42] 
$Q=\sum_{q_{\min }}^{q_{\max }}\left(I\left(q_{i}\right)-b\right) q_{i}^{2} \Delta q_{i}+K / q_{\max }$

where $b$ is a constant determined using equation

$I(q) q^{4}=K+b q^{4}$

valid in the Porod range.

The $G(h)$ curves (Fig. 9) show that carbonization of resorcinol-formaldehyde resin

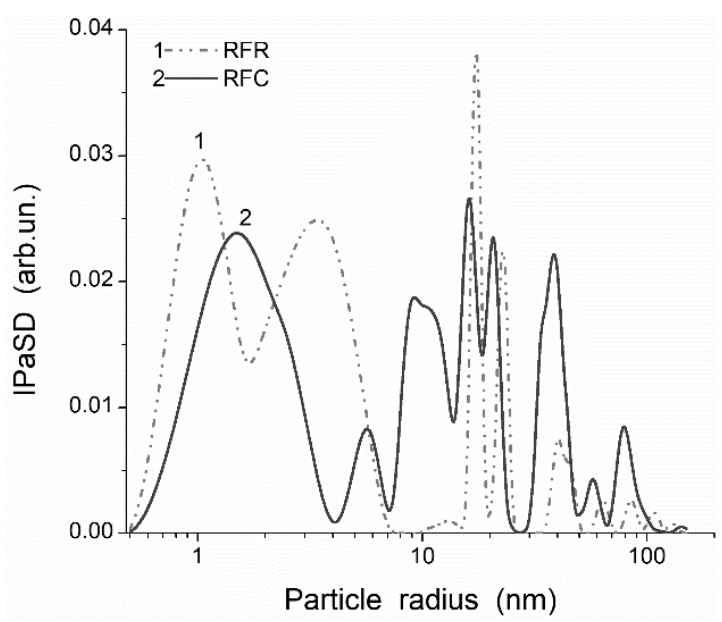

Fig. 8. Particle size distributions of resorcinolformaldehyde resin/bentonite $\left(S_{\mathrm{BET}}=160 \mathrm{~m}^{2} / \mathrm{g}\right.$ and $\left.S_{\mathrm{SAXS}}=194 \mathrm{~m}^{2} / \mathrm{g}\right)$ and char/bentonite $(20 / 80 \mathrm{w} / \mathrm{w})$ composite $\left(S_{\mathrm{BET}}=122 \mathrm{~m}^{2} / \mathrm{g}\right.$ and $S_{\mathrm{SAXS}}=211 \mathrm{~m}^{2} / \mathrm{g}$ ), prepared upon carbonization of resorcinol-formaldehyde resin added to bentonite, calculated using SAXS/SCR method with a complex model with spherical, cylindrical and lamellar particles (Eq. (12)) (some details were described elsewhere [37])

Note that the SAXS data treatments described above were successfully used for carbon, silica, and polymeric materials in comparison with the results of various methods used to analyze the nitrogen adsorption data [37, 38, 43-45] or analysis of microscopic images. Additional not only morphological but also textural quantitative characteristics could be derived from adsorption and SAXS data, as well from TEM and SEM images.

\section{HIGH-RESOLUTION TRANSITION ELECTRON MICROSCOPY (HRTEM)}

TEM and SEM images (Fig. 10) could be used to calculate both PSD [16, 28] and PaSD (Figs. 2 and $11 a$ ) functions. However, this needs certain methods (computer programs) for image bound to bentonite particles results in diminution of the thickness of pore walls over the total range. The carbonization results in a decrease in the value of $S_{\text {BET }}\left(160 \mathrm{~m}^{2} / \mathrm{g} \rightarrow 122 \mathrm{~m}^{2} / \mathrm{g}\right)$ due to consolidation of particles that causes an increase in a part of closed pores since the $S_{\text {SAXs }}$ value increases $\left(194 \mathrm{~m}^{2} / \mathrm{g} \rightarrow 211 \mathrm{~m}^{2} / \mathrm{g}\right)$ during the carbonization (Fig. 9). Thus, the SAXS method gives useful information on global textural changes in the materials that significantly completes the adsorption data.

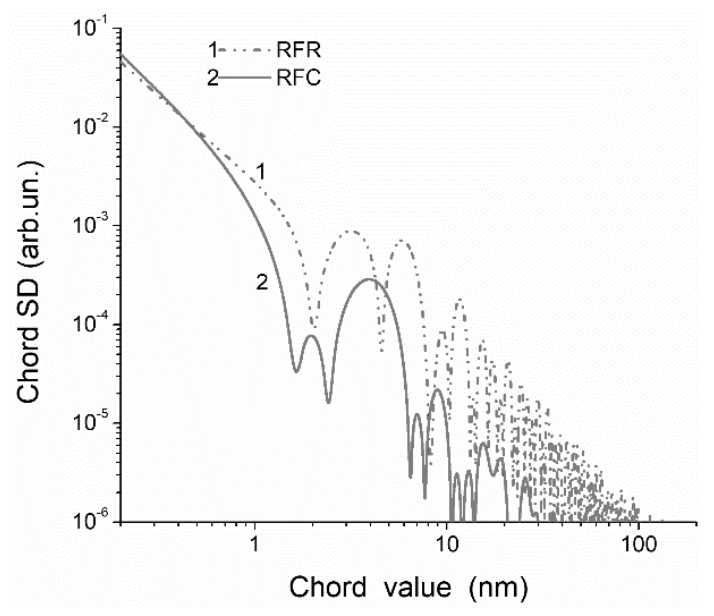

Fig. 9. Chord size $G(h)$ distributions of resorcinolformaldehyde resin/bentonite $\left(S_{\mathrm{BET}}=160 \mathrm{~m}^{2} / \mathrm{g}\right.$ and $\left.S_{\mathrm{SAXS}}=194 \mathrm{~m}^{2} / \mathrm{g}\right)$ and char/bentonite $(20 / 80 \mathrm{w} / \mathrm{w})$ composite $\left(S_{\mathrm{BET}}=122 \mathrm{~m}^{2} / \mathrm{g}\right.$ and $\left.S_{\mathrm{SAXS}}=211 \mathrm{~m}^{2} / \mathrm{g}\right)$, prepared upon carbonization of resorcinol-formaldehyde resin added to bentonite, calculated using SAXS method with Eq. (13) (some details were described elsewhere [37])

treatment using, e.g., such software as ImageJ [46] (with a granulometry plugin), Fiji [47] (with a local thickness plugin) or others [48]. The quantitative analyses of microscopic images have certain advantages and disadvantages described in detail elsewhere [48]. The advantages are due to practically direct quantitative information on the particulate morphology and texture of the materials studied that can be compared with the results based on indirect information based, e.g. on the adsorption and SAXS data. The disadvantages of the approaches are due to certain problems of quantitative analysis of images, especially pore walls and pore sizes, with a certain ambiguity of their representation on gray-scale images [48]. 
Figure 10 shows images of fresh A-300 and aged (about 15 years) A-500. The latter lost the surface area from $492 \mathrm{~m}^{2} / \mathrm{g}$ (fresh) to $331 \mathrm{~m}^{2} / \mathrm{g}$ (aged). This effect is caused by enhanced aggregation of NPNP (comp. Figs. 10 a-d and $10 e, f)$ that results in significant changes in the nitrogen adsorption-desorption isotherm
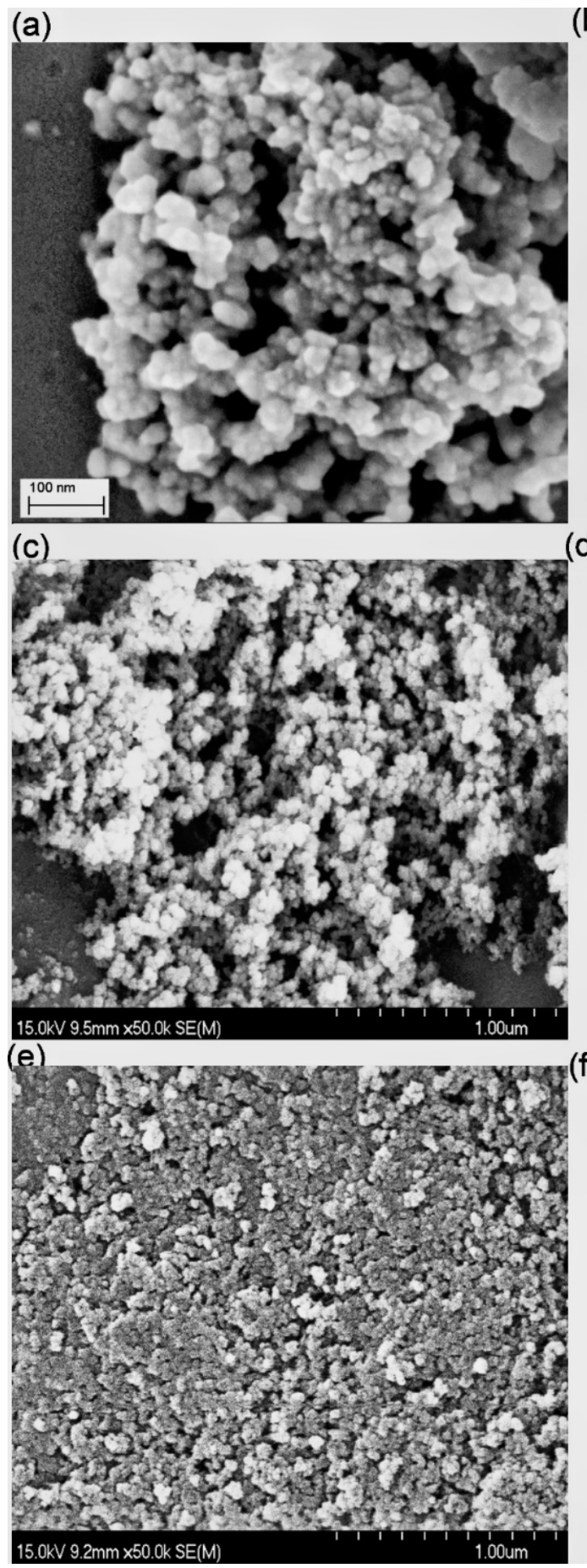

(d)
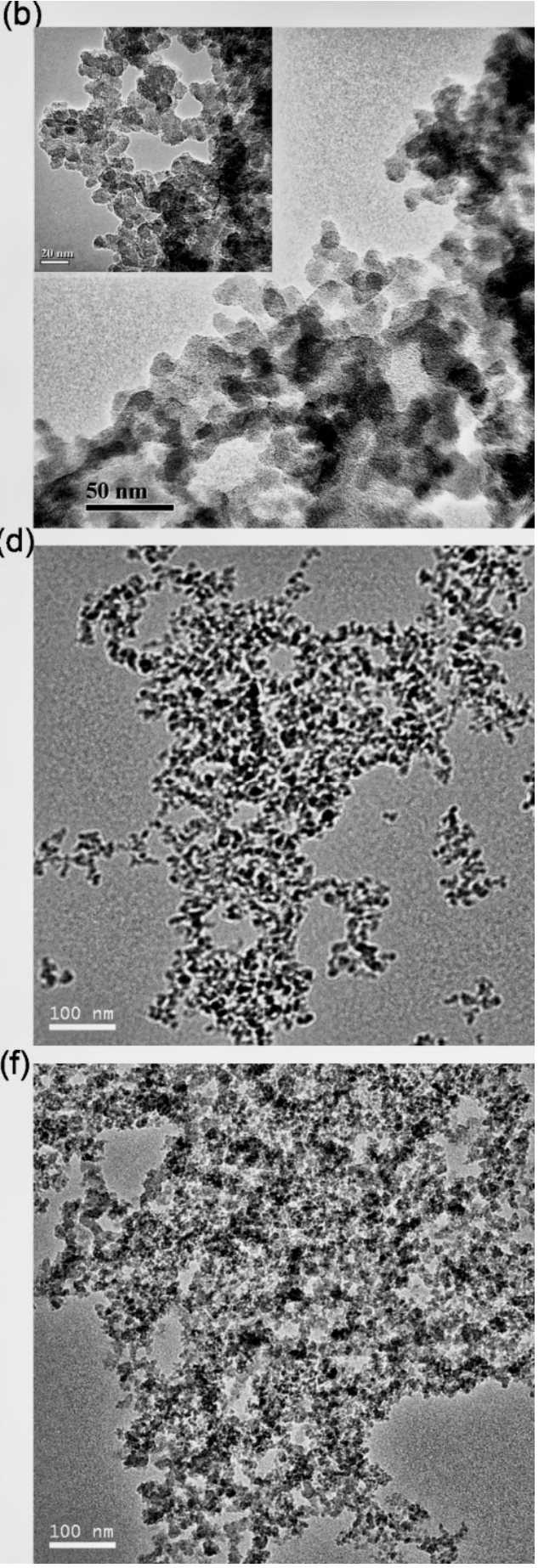

Fig. 10. $(a, c, e)$ SEM and $(b, d, f)$ TEM images of $(a, b, c, d)$ fresh A-300 and $(e, f)$ A-500 (aged during 15 years) showing NPNP aggregates and agglomerates of aggregates
(Fig. $11 a$ ) and PSD (Fig. 11 b). These textural changes over the total range of pores (voids between NPNP) are similar (but slightly different) to those observed after the mechanical compaction of the FMO powders described above. 
Thus, FMO based on amorphous silica or other amorphous silicas (which are a hard-moving liquid), e.g. silica gels, are aged-time-sensitive materials. This time-dependent aggregation effect is of importance from a practical point of view.
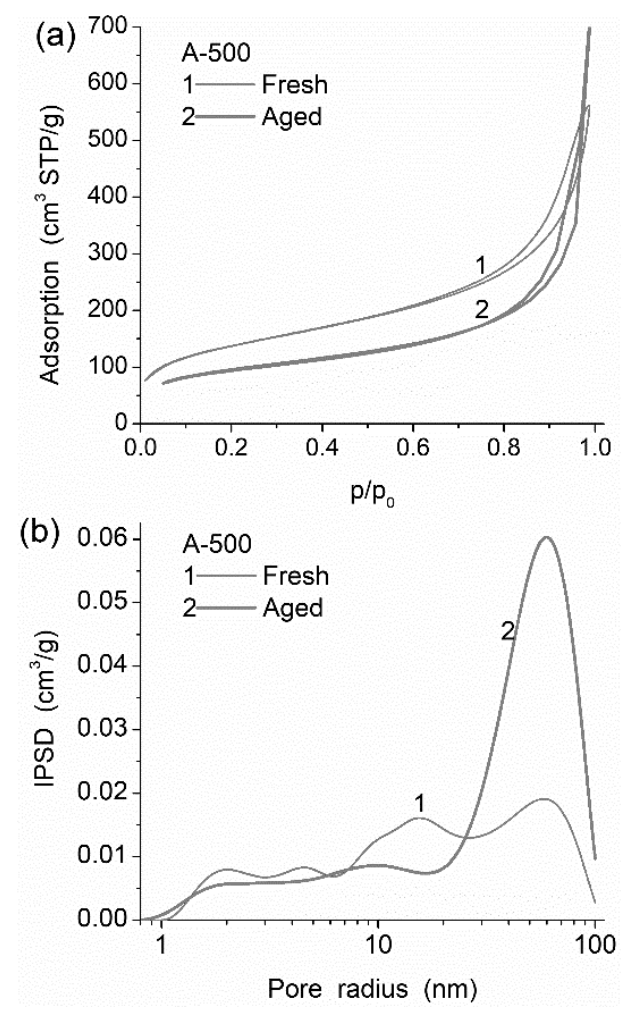

Fig. 11. (a) Nitrogen adsorption-desorption isotherms for fresh (1) and 15-years aged A-500 (2) and (b) V/DFT PSD (based on Eqs. (4)-(6))

\section{QUASI-ELASTIC LIGHT SCATTERING}

The characteristics of such highly disperse materials as FMO depend strongly on the dispersion media properties because of several factors: (i) surface charging, (ii) NPNP swelling, (iii) colloidal stability and aggregation instability and others [16-20, 49-51]. Electrophoretic mobility and secondary particle size distribution (SPSD) investigations could be performed using such apparatus based on the quasi-elastic light scattering (QELS) (photon correlation spectroscopy, static light scattering, or dynamic light scattering) method as a Zetasizer 3000 (Malvern Instruments). Deionized distilled water and FMO samples (1-30 g per $\mathrm{dm}^{3}$ of the water) could be utilized to prepare suspensions sonicated for several min using an ultrasonic disperser (e.g. Sonicator Misonix, power $500 \mathrm{~W}$ and frequency $22 \mathrm{kHz}$ ). The $\mathrm{pH}$ values could be adjusted by addition of $0.1 \mathrm{M} \mathrm{HCl}$ or $\mathrm{NaOH}$ solutions, and the salinity could be changed by addition of $\mathrm{NaCl}$, $\mathrm{NaClO}_{4}$, etc. The electrophoretic behavior and the SPSD with respect to the intensity of scattered light $\left(\mathrm{SPDS}_{\mathrm{I}}\right)$ and particle number $\left(\mathrm{SPDS}_{\mathrm{N}}\right)$ of FMO in the aqueous suspensions were described in detail elsewhere $[16,18,49,50]$.
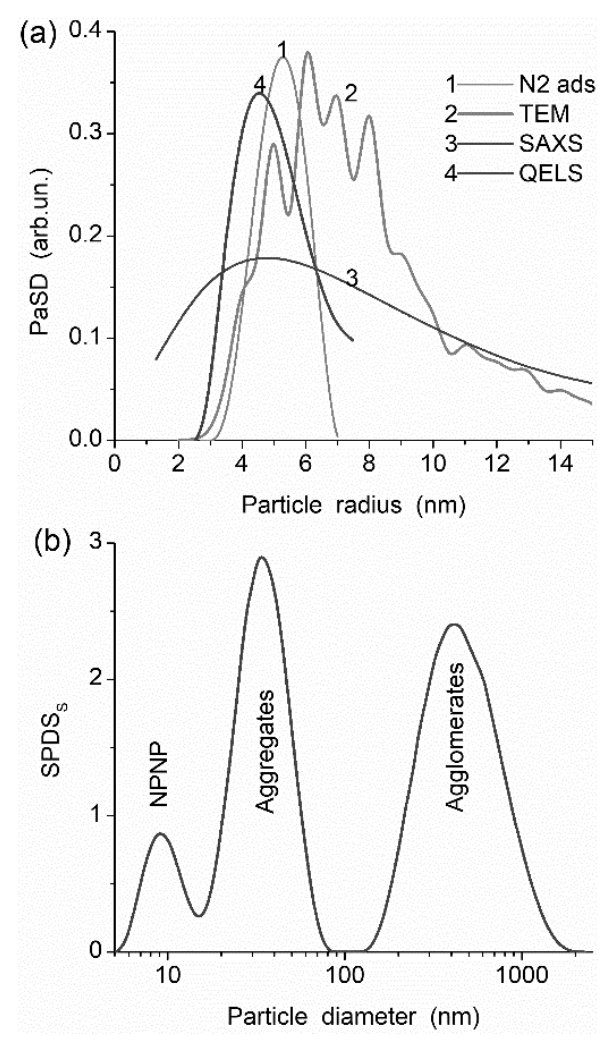

Fig. 12. (a) Primary nanoparticle size distributions of A-300 $\left(S_{\mathrm{BET}}=294 \mathrm{~m}^{2} / \mathrm{g}\right)$ estimated from the data of nitrogen adsorption (V/SCR method), HRTEM (ImageJ with granulometry plugin [46]), SAXS (with a model of spherical particles), and QELS (a model of spherical particles); and (b) particle size distribution $\left(\mathrm{SPSD}_{\mathrm{S}}\right)$ in aqueous suspension of A-300 $\left(S_{\mathrm{BET}}=330 \mathrm{~m}^{2} / \mathrm{g}\right.$, concentration of 3 wt. \%)

According to the Smoluchowski theory [51], there is a linear relationship between the electrophoretic mobility $U_{\mathrm{e}}$ (QELS measured) and the $\zeta$ potential: $U_{\mathrm{e}}=A \zeta$, where $A$ is a constant for a thin electrical double layer (EDL) at $\kappa a>>1$ (where $a$ denotes the particle radius, and $\kappa$ is the Debye-Huckel parameter). For a thick EDL $(\kappa a<1), e . g$., at $\mathrm{pH}$ close to the isoelectric point (IEP), the equation with the Henry correction factor is more appropriate $U_{\mathrm{e}}=2 \varepsilon \zeta /(3 \eta)$, where $\varepsilon$ is the dielectric permittivity; and $\eta$ is the viscosity of the liquid [51]. For FMO dispersions in the aqueous media, aggregation of NPNP is 
always characteristic [49, 50]. However, sometimes the first peak of SPSD (Fig. $12 a$, curve 4) corresponds to NPNP. The hydrodynamic diameter of NPNP could be 5-20\% larger than the geometric one due to the presence of an immobile layer in EDL of liquid/bound counter ions depending on $\mathrm{pH}$, IEP, salinity, etc. Other peaks in the SPSD correspond to NPNP aggregates and aggregates/agglomerates (Fig. $12 b$ ). Note that QELS PaSD peak of NPNP corresponds to smaller sizes than that estimated from TEM image and nitrogen adsorption data because there were different A-300 samples with $330 \mathrm{~m}^{2} / \mathrm{g}$ (QELS) and $294 \mathrm{~m}^{2} / \mathrm{g}$ (TEM, nitrogen adsorption). Thus, the QELS method could be used to estimate the aggregation of FMO particles in liquid dispersion media depending on conditions of the measurements. This FMO behavior can affect the results of the NMR cryoporometry and relaxometry investigations of the suspensions.

\section{NMR CRYOPOROMETRY}

The confined space effects play an important role for liquid adsorbates or dispersion media (e.g. water, etc.) especially at temperatures lower than freezing temperature of bulk liquid that can be utilized in various methods to estimate the textural characteristics on the base of the temperature behavior of liquids confined in pores $[16,18,19,52-54]$. Water can be frozen in narrower pores (or voids between nanoparticles) at lower temperatures as described by the Gibbs-Thomson (GT) relation for the freezing point depression for liquids confined in cylindrical pores at radius $R[16,52-54]$

$\Delta T_{m}=T_{m, \infty}-T_{m}(R)=-\frac{2 \sigma_{s l} T_{m, \infty}}{\Delta H_{f} \rho R}=\frac{k_{G T}}{R}$,

where $T_{\mathrm{m}}(R)$ is the melting temperature of ice in cylindrical pores of radius $R, T_{\mathrm{m}, \infty}$ the bulk melting temperature, $\Delta H_{\mathrm{f}}$ the bulk enthalpy of fusion, $\rho$ the density of the solid, $\sigma_{\mathrm{sl}}$ the energy of solid-liquid interaction, and $k_{\mathrm{GT}}$ is the Gibbs-Thomson constant $\left(k_{\mathrm{GT}}=40-90 \mathrm{~K} \mathrm{~nm}\right.$ for various FMO, porous oxides (silica gels), polymers, carbons, etc.). Eq. (18) could be used to determine the cluster size distributions (CSD) $\left(f_{\mathrm{V}}(R)=d V_{\mathrm{uw}}(R) / d R\right)$ of water unfrozen at $T<273 \mathrm{~K}[16]$ and bound to disperse or porous solids wetted or located in the aqueous suspensions.
Eq. (18) can be transformed into Eq. (19) for two (or more if their signals could be separated in total spectra deconvoluted) immiscible liquids (e.g. water and benzene characterized by different ${ }^{1} \mathrm{H}$ NMR signals $\left.[16,27]\right)$ with consideration for their amounts in a mixture and their temperaturedependent signal intensity (obtained on deconvolution of the total signal)

$$
\frac{d V_{u, i}}{d R}=\frac{A_{i}}{k_{i}}\left(T-T_{m, \infty, i}\right)^{2} \frac{d C_{u, i}}{d T},
$$

where $i$ denotes an adsorbate number, $C_{\mathrm{u}, i}(T)$ is the integral intensity of a $\delta_{\mathrm{H}}$ band for the $i$-th adsorbate as a function of temperature, and $A_{i}$ is a weight constant dependent on the molecular volume $\left(v_{i}\right)$, the number of protons $\left(n_{i}\right)$ in a molecule of the $i$-th adsorbate and the used units. Eq. (19) can be transformed into integral GT (IGT) equation, replacing $d V / d R$ by $f(R)$, converting $d C / d T$ to $d C / d R$ and integrating by $R$,

$$
C_{u, i}(T)=A \int_{R_{\min }}^{R_{\max }}\left(\frac{k_{i}}{\left(T_{m, \infty, i}-T_{m, i}(R)\right) R}\right)^{2} f_{i}(R) d R .
$$

CSD could be converted into incremental CSD (ICSD) $\Phi_{\mathrm{V}}\left(R_{i}\right)=\left(f_{\mathrm{V}}\left(R_{i+1}\right)+f_{\mathrm{V}}\left(R_{i}\right)\right)\left(R_{\mathrm{i}+1}-\right.$ $\left.R_{\mathrm{i}}\right) / 2$ at $\sum \Phi_{\mathrm{V}, \mathrm{i}}(R)=V_{\text {uw. }}$. Integration of the $f_{\mathrm{V}}(R)$ and $f_{\mathrm{S}}(R)$ functions at $R<1 \mathrm{~nm}, 1 \mathrm{~nm}<R<25 \mathrm{~nm}$, and $25 \mathrm{~nm}<R<100 \mathrm{~nm}$ gives the volume and specific surface area of nano-, meso- and macropores, respectively, filled by unfrozen liquid. The specific surface area $\left(S_{\mathrm{uw}}\right)$ of adsorbents in contact with bound water (assuming for simplicity that the density of unfrozen bound water $\rho_{\text {uw }}=1 \mathrm{~g} / \mathrm{cm}^{3}$ ) can be determined from the amount of this water $C_{u w}^{\max }$ (estimating pore volume as $\left.V_{\mathrm{uw}}=C_{u w}^{\max } / \rho_{\mathrm{uw}}\right)$ at $273 \mathrm{~K}$ and pore size distribution $f(R)$ with a model of cylindrical pores [16]

$$
S_{u w}=\frac{V_{u w}}{2 R_{a v}}=\frac{2 C_{u w}^{\max }}{\rho_{u w}} \int_{R_{\min }}^{R_{\max }} f(R) d R / \int_{R_{\min }}^{R_{\max }} f(R) R d R,
$$

where $R_{\min }$ and $R_{\max }$ are the minimal and maximal radii of pores filled by unfrozen water, respectively. In the case of calculations of the structural characteristics of nanopores $(R<1 \mathrm{~nm})$, mesopores $(1 \mathrm{~nm}<R<25 \mathrm{~nm})$ and macropores ( $R>25 \mathrm{~nm}$ ), the $R_{\min }$ and $R_{\max }$ values are the boundary $R$ values for the corresponding pore types (including $R_{\min }=0.2 \mathrm{~nm}$ for nanopores). 
The $C_{u w}^{\max } / \rho_{u w}$ value should be replaced by the corresponding values of the volumes of nanopores, mesopores, or macropores [16]. The average melting temperature $\left\langle T_{\mathrm{m}}\right\rangle$ could be calculated using formula related to the ratio of the first and zero moments of the distribution function [20]

$$
<T_{m}>=\int_{T_{\min }}^{T_{0}} T C_{u w}(T) d T / \int_{T_{\min }}^{T_{0}} C_{u w}(T) d T,
$$

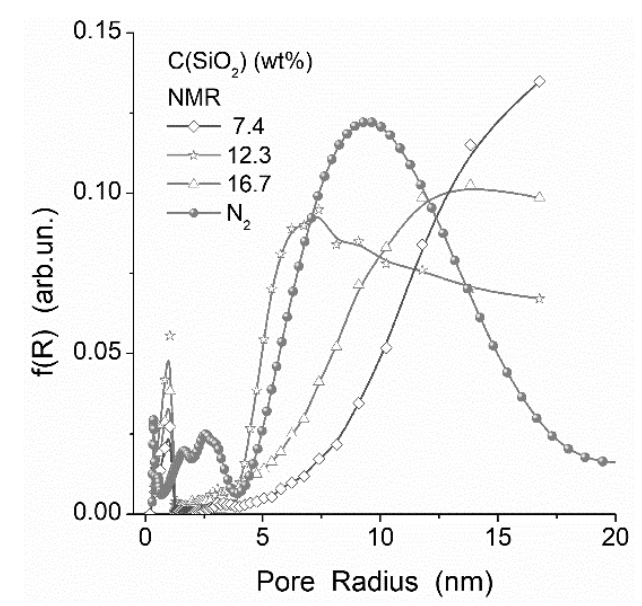

Fig. 13. Size distributions of pores (nitrogen adsorption/desorption treated with $\mathrm{V} / \mathrm{SCR}$ method) and clusters with unfrozen water $(T<273 \mathrm{~K})$ filling voids between silica (A-300) NPNP in aggregates located in aqueous suspensions at different concentration of silica (GT method) (some details were described elsewhere [16])

The NMR cryoporometry gives useful information on the behavior of bound water depending not only on the silica (water) content, but also on the A-300 treatment (e.g. MCA) effects (Fig. 14). A strong increase in the content of water from $h=3 \mathrm{~g} / \mathrm{g}$ (wetted powder) to $40.7 \mathrm{~g} / \mathrm{g}$ (suspension) results in a relative decrease in the content of strongly bound water forming small clusters in narrow voids because in the suspension, the average distance between NPNP can strongly increase (due to electrostatic repulsion interactions). The MCA compaction of A-300 results in a relative increase in contribution of small clusters $(R<2 \mathrm{~nm})$ because contribution of narrow voids increases (Figs. 3 and 14). An enhancement in the MCA compaction resulting in where $T_{0}=273.15 \mathrm{~K}$, and $T_{\min }$ is the temperature corresponding to $C_{\mathrm{uw}}=0$.

Fig. 13 shows the $f(R)$ functions for the aqueous suspensions of A-300 at different concentrations of silica in comparison to the $\mathrm{N}_{2}$ adsorption PSD (V/SCR). The value of $C_{\mathrm{A}-300}=12.3 \mathrm{wt} . \%$ is close to that causing complete structurization (clusterization) of the dispersion [16]. Therefore, changes in the $f(R)$ curves are non-monotonic with increasing $C_{\mathrm{A}-300}$ value due to different structurization of the dispersion vs. A-300 concentration.

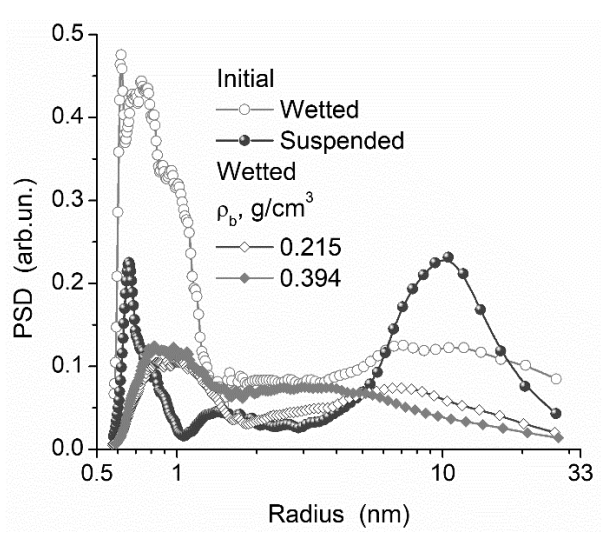

Fig. 14. Differential functions with respect to the sizes of unfrozen water structures for hydrated silicas ( $h=3.0,40.7,1.2$ and $1.0 \mathrm{~g} / \mathrm{g}$, respectively) with the specific surface area in contact with unfrozen water $S_{\text {uw }}=322,281,123,124 \mathrm{~m}^{2} / \mathrm{g}$, respectively (additional details are elsewhere [34])

a greater $\rho_{b}$ value (from 0.22 to $0.39 \mathrm{~g} / \mathrm{cm}^{3}$ ) slightly affects the distribution of unfrozen water clusters in wetted samples over the total size range (Fig. 14) because the PSD changes too (Fig. 3), but the water content is not enough to strongly change the NPNP aggregation that observed in the aqueous suspensions. Thus, NMR cryoporometry gives information not only on the textural characteristics of the materials being in different dispersion media but also on the temperature behavior of unfrozen liquids confined in different pores. Similar information could be obtained using the DSC thermoporometry method based on the Gibbs-Thomson relation for the melting point depression for liquids confined in pores. 


\section{DSC THERMOPOROMETRY}

Melting DSC curves of bound water (ice) [55-58] can be used to calculate the pore sizes filled by this water as follows:

$R_{p}(n m)=0.68-\frac{32.33}{T_{m}-T_{m 0}}$,

where $T_{\mathrm{m}}$ and $T_{\mathrm{m} 0}$ are the melting temperatures of confined and bulk water, respectively. The pore size distribution $d V / d R$ can be calculated from the DSC melting curves of bound ice

$\frac{d V}{d R}\left(\mathrm{~cm}^{3} \mathrm{~nm}^{-1} \mathrm{~g}^{-1}\right)=\frac{\frac{d q}{d t}\left(T_{m}-T_{m 0}\right)^{2}}{32.33 \rho \beta m \Delta H(T)}$,

where $d q / d t, \rho, \beta, m$ and $\Delta H(T)$ are the DSC heat flow, the water density, the heating rate, the sample mass and the melting enthalpy of ice, respectively. The $\Delta H$ values as a function of temperature for water can be estimated as follows [55-58]

$$
\begin{aligned}
& \Delta H(T)\left(\mathrm{J} \mathrm{g}^{-1}\right)=332+11.39\left(T_{m}-T_{m 0}\right)+ \\
& +0.155\left(T_{m}-T_{m 0}\right)^{2} .
\end{aligned}
$$

The Gibbs-Thomson equation applied to DSC melting thermograms allows one to accurate calculate the PSD for silica gels (with the model of cylindrical pores since the errors of this model are relatively small for silica gels $[16,17])$ using melting curves at $T<T_{\mathrm{f}}$, i.e. using the lowtemperature DSC peaks [60]. Melting curves of $n$-decane at $T<243 \mathrm{~K}$ could be used to calculate the PSD for silicas with the GT equation $R=k_{\mathrm{GT}} /\left(T_{0, \mathrm{~m}}-T_{\mathrm{m}}\right)$ for cylindrical pore radius at $k_{\mathrm{GT}}=64.6 \mathrm{~K} \mathrm{~nm}$, where $T_{0, \mathrm{~m}}$ and $T_{\mathrm{m}}$ were the melting temperatures for pure bulk crystallites and confined in pores of radius $R$, respectively. For the freezing point depression of $n$-decane confined in pores (voids), these calculations resulted in the PSD similar to the NLDFT PSD [28]. For water as a probe, there are certain differences between nitrogen adsorption PSD and DSC PSD for different silicas (Fig. 15) that is due to several factors: (i) water can be layer-by-layer frozen in mesopores and macropores; (ii) ice (having a larger volume than liquid water) can affects the PSD; (iii) model errors caused by the difference between model pore shape (e.g. cylindrical) and real one (e.g. voids between NPNP). However, qualitative changes in the DSC
PSD and adsorption PSD are similar upon the MCA compaction of A-300 (Fig. $15 a$ ). The DSC thermoporometry $[16,28,55-60]$, as well thermogravimetry porometry $[28,61]$ could be used for the characterization of the behavior of adsorbates at low and high temperatures that gives additional information on the confined space effects important on practical applications of the materials under different conditions. Note that the confined space effects can be observed not only for unfrozen liquids but also for frozen ones using the TSDC method [62].
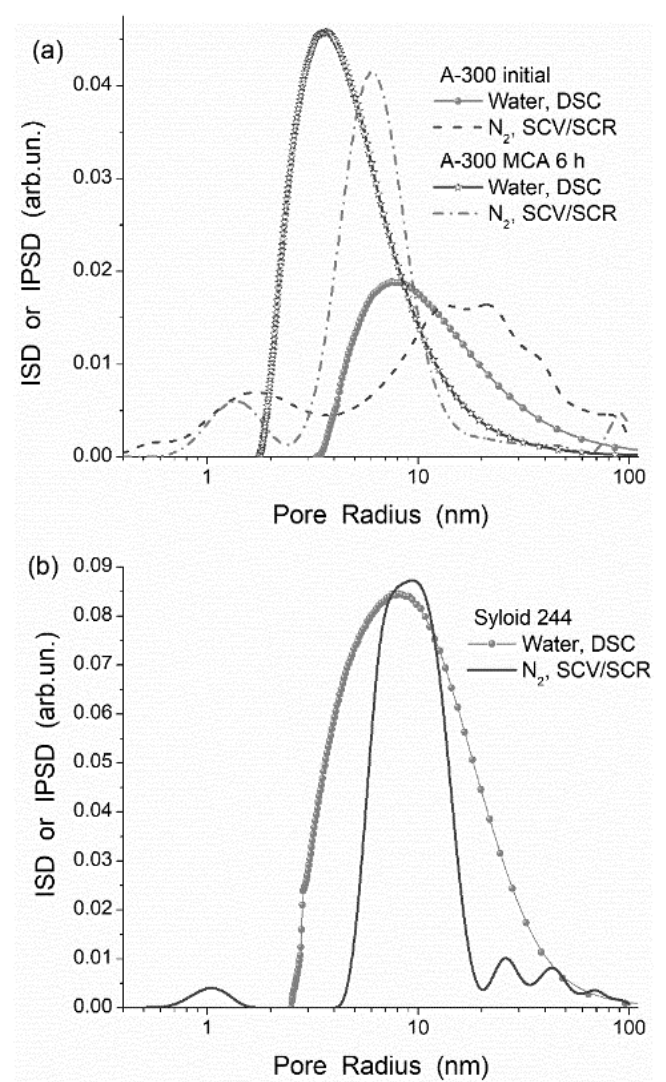

Fig. 15. Comparison of the IPSD calculated from nitrogen adsorption-desorption isotherms and ISD based on the DSC melting thermograms of water (ice) bound to (a) initial A-300 $\left(S_{\mathrm{BET}}=331 \mathrm{~m}^{2} / \mathrm{g}, V_{\mathrm{p}}=0.826 \mathrm{~cm}^{3} / \mathrm{g}\right), \mathrm{MCA} 6 \mathrm{~h}$ A-300 $\left(S_{\mathrm{BET}}=331 \mathrm{~m}^{2} / \mathrm{g}, V_{\mathrm{p}}=0.771 \mathrm{~cm}^{3} / \mathrm{g}\right)$, and $(b)$ Syloid $244\left(S_{\mathrm{BET}}=336 \mathrm{~m}^{2} / \mathrm{g}\right.$, $V_{\mathrm{p}}=1.591 \mathrm{~cm}^{3} / \mathrm{g}$ ) (some details were described elsewhere [60])

\section{TSDC RELAXOMETRY}

Thermally stimulated (de)polarization current (TSDC) method could be used to analyze the confined space effects for frozen polar liquids (e.g. water $\rightarrow$ ice) bound to various disperse or porous solids even at low their content, i.e., 
diluted aqueous suspensions could be studied due to high sensitivity of the TSDC method measuring low depolarization currents at $10^{-15}-10^{-7} \mathrm{~A}$ [62]. The tablets (diameter $30 \mathrm{~mm}$, thickness $\sim 1 \mathrm{~mm}$ ) with frozen studied materials differently hydrated (hydration $h=0.03-99$ gram of water per gram of a dry material) could be polarized by the electrostatic field at the intensity $F_{\mathrm{p}}=0.1-0.5 \mathrm{MV} / \mathrm{m}$ at $260-265 \mathrm{~K}$ then cooled to 80-90 K with the field still applied and heated without the field to $265-270 \mathrm{~K}$ at a various heating rate $($ e.g. $\beta=0.05 \mathrm{~K} / \mathrm{s})$. The current $(I)$ evolving due to sample depolarization could be recorded by an electrometer over the $10^{-15}-10^{-7} \mathrm{~A}$ range. Relative mean errors for measured TSDC are relatively small $\delta_{\mathrm{I}}= \pm 5 \%, \delta_{\mathrm{T}}= \pm 2 \mathrm{~K}$ for temperature, $\delta_{\beta}= \pm 5 \%$ for the temperature change rate [62].

The temperature range on the TSDC measurements is much broader $(80-270 \mathrm{~K})$ than that on the ${ }^{1} \mathrm{H}$ NMR measurements (180-290 K) because the dipolar relaxation (TSDC)

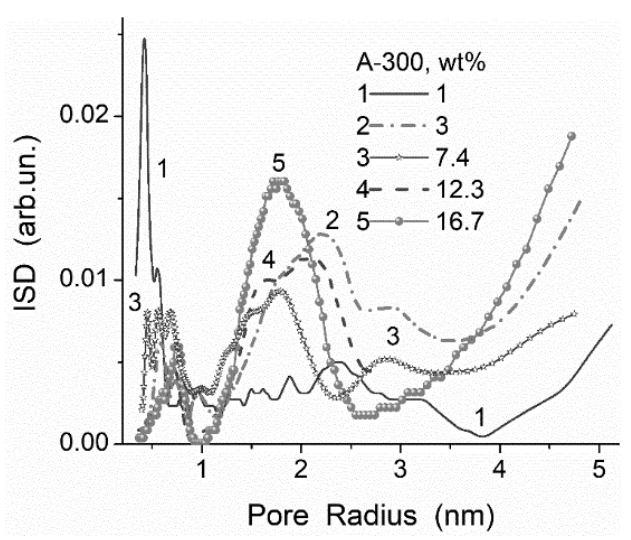

Fig. 16. Size distributions of water clusters located in voids between silica NPNP in aggregates located in frozen aqueous suspensions of A-300 (TSDC/GT method) at different concentrations (some details were described elsewhere [62])

Similar to the ${ }^{1} \mathrm{H}$ NMR cryoporometry results for the A-300 suspensions (Fig. 13) the water cluster distributions based the TSDC data (Fig. 16) demonstrate nonmonotonic changes in the nanostructured clusters $(R<1 \mathrm{~nm})$ and mesostructured clusters and domains ( $R=1-5 \mathrm{~nm})$ with increasing concentration of observed at $T<200-220 \mathrm{~K}$ is linked to the polar bond rotations or molecular fragment relaxation (observed in confined ice) which cannot be registered in the ${ }^{1} \mathrm{H}$ NMR spectra (of static samples with narrow bandwidth of $20 \mathrm{kHz}$ [16]) of mobile low-molecular molecules (water, benzene, acetone, etc.) that appears only at higher temperatures. However, the temperature ranges of the throughout conductivity ( $\mathrm{dc}$ relaxation in TSDC) and the molecular mobility $\left({ }^{1} \mathrm{H}\right.$ NMR) are relatively close but not the same $[16,62]$ because the dc relaxation requires the throughout percolation of ions in the samples from one electrode to another, but the molecular mobility reflected in the ${ }^{1} \mathrm{H}$ NMR spectra can be due to local (cluster) mobility of bound or bulk water (from individual molecules, clusters, nanodomains to bulk water with elevating temperature). Therefore, the dc relaxation in TSDC is observed at slightly higher temperature than the ${ }^{1} \mathrm{H}$ NMR spectra of unfrozen clusters of confined water $[16,62]$.

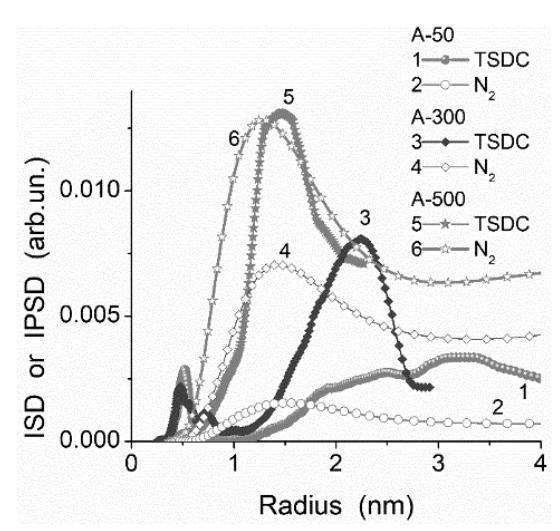

Fig. 17. Size distributions of pores (nitrogen adsorption/desorption treated with SCV/SCR method) and water clusters located in voids between silica NPNP in aggregates located in frozen aqueous suspensions of A-50, A-300, and A-500 (TSDC/GT method) at 7 wt. \% (some details were described elsewhere $[16,62])$

silica in the aqueous suspensions. However, for different nanosilicas such as A-50 $\left(S_{\mathrm{BET}}=52 \mathrm{~m}^{2} / \mathrm{g}\right), \mathrm{A}-300\left(294 \mathrm{~m}^{2} / \mathrm{g}\right)$, and A-500 $\left(492 \mathrm{~m}^{2} / \mathrm{g}\right)$, there are practically monotonic changes in the cluster sizes and their contributions (Fig. 17) because the smaller the NPNP size, the stronger the aggregation of 
NPNP affecting the TSDC spectra of confined water (ice). Note that integral GT equation based on the TSDC relaxation vs. temperature (similar to integral GT equation (20) for NMR cryoporometry but with a certain dependence of $k_{\mathrm{GT}}$ on $\left.T[16,62]\right)$ gives the $f(R)$ function close to the $\mathrm{N}_{2}$ PSD than that calculated using nonintegral equation (Fig. 18). Thus, the TSDC relaxation data could be used for additional characterization of confined liquids at $T<T_{\mathrm{f}}$ when only dipolar relaxation of bonds and certain atomic fragments is observed in ice (i.e. with no the molecular mobility for confined unfrozen liquids observed in the NMR cryoporometry or DSC thermoporometry). TSDC relaxometry characterized by certain advantages and disadvantages, as well other described methods, gives additional information allowing one a deeper insight into the interfacial phenomena and more complete characterization of the materials in different conditions.

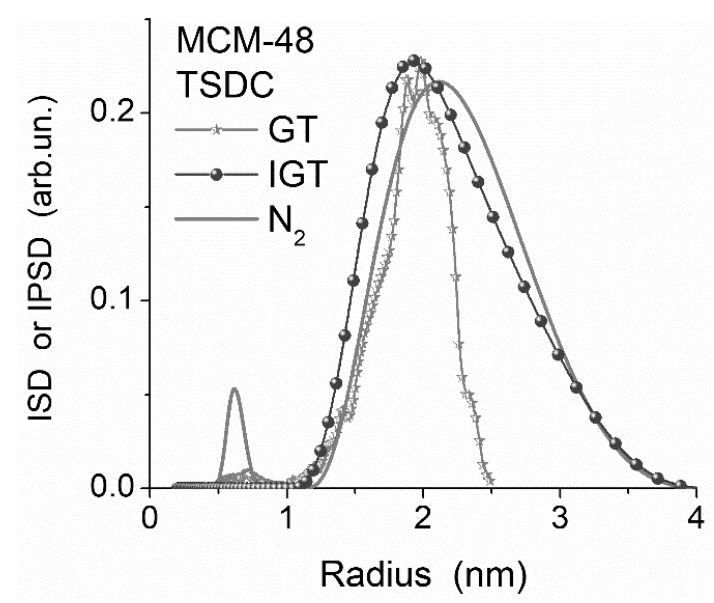

Fig. 18. Size distributions of pores (nitrogen adsorption/desorption treated with a model of cylindrical pores) and water clusters located in pores of MCM-48 located in frozen aqueous suspension (TSDC/GT and integral GT methods) at 16.7 wt. \% (some details were described elsewhere $[16,62]$ )

\section{CONCLUSION}

The present study deals with analyses of a set of methods used to investigate the morphological and textural characteristics of nano/meso/macroporous materials being in various dispersion media, as well the interfacial phenomena basic for various approaches in the characterization of materials. There are several ways in these studies: (i) adsorption-desorption of low-molecular weight probe compounds $\left(\mathrm{N}_{2}, \mathrm{Ar}\right.$, etc.); (ii) adsorption or confinement of low- or high-molecular weight compounds in pores (voids) of solid particles being in liquid media; (iii) small angle X-ray scattering (SAXS); (iv) quantitative analysis of images recorded using various microscopic methods; (v) thermoporometry based on differential scanning calorimetry (DSC) with decreasing-increasing temperature using melting thermograms; (vi) cryoporometry based on low-temperature ${ }^{1} \mathrm{H}$ NMR spectroscopy giving the dependence of signal intensity of a mobile phase vs. temperature; (vii) relaxometry based on NMR spectroscopy with transverse relaxation time $v s$. temperature; and (viii) relaxometry based on thermally stimulated depolarization current (TSDC) measurements. Each method could be characterized by certain systematic errors. However, the use of several aforementioned methods in parallel can allow one to elucidate the reasons and level of systematic errors that is on importance for correct characterization of the materials studied. Thus, the larger the number of in parallel used methods, the more comprehensive the morphological and textural characterization of the adsorbents.

One of the main effects of liquid dispersion media onto FMO is changes in the organization of the secondary particles, i.e. NPNP aggregates and agglomerates of aggregates, that nonmonotonically depends on the concentration of FMO and typically the secondary particles become less compacted. The opposite effect is due to any mechanical loading on dry or wetted FMO powders, which become more compacted. 


\title{
Характеризація нано/мезо/макропористих матеріалів у залежності від експериментальних умов та особливостей методів, що використовуються
}

\author{
В.М. Гунько \\ Інститут хімії поверхні ім. О.О. Чуйка Національної академії наук України \\ вул. Генерала Наумова, 17, Київ, 03164, Україна, vlad_gunko@ukr.net
}

\begin{abstract}
Метою иього дослідження був аналіз різних методів, що використовують для характеризації морфології та текстури матеріалів, які перебувають у різних дисперсійних середовищах, а також явищ на межах поділу, що $\epsilon$ основою різних використаних методів. $С$ декілька шияхів в аналогічних дослідженнях: (i) адсорбиія-десорбиія низькомолекулярних сполук ( $N_{2}, A r$ тощо); (ii) адсорбція чи обмеження у просторі пор низько- чи високомолекулярних сполук при взаємодї з твердими частинками у рідкому середовищі; (iii) малокутове розсіяння рентгенівських променів або нейтронів; (iv) числовий аналіз мікрозображень ТЕМ, СЕМ тощо; (v) термопорометрія на основі диферениійної скануючої калориметрії з використанням термограм плавлення; (vi) кріопорометрія на основі низькотемпературної ЯМР спектроскопії щодо залежності інтенсивності сигналів від температури, нижчої за температуру замерзання вільної рідини; (vii) релаксометрія на основі ЯМР спектроскопії щодо температурної залежності часу поперечноїрелаксаиіï; та (viii) релаксометрії на основі залежності струму термостилульованої деполяризаиії від температури. Кожен з иих методів може характеризуватися певними систематичними похибками. Проте паралельне використання кількох методів дозволяє визначити причини та рівень систематичних помилок, що є важливим для коректної характеризації матеріалів, що досліджуються в різних середовищах. Таким чином, чим більще методів використовується у паралельних дослідженнях, тим більш надійною і повною може бути морфологічна та текстурна характеризація адсорбентів різної природи.
\end{abstract}

Ключові слова: пірогенні оксиди, мезопористі кремнеземи, силікагель, активоване вугілля, морфологія частинок, текстурні характеристики, систематичні помилки

\section{Характеризация нано/мезо/макропористых материалов в зависимости от экспериментальных условий и особенностей использованных методов}

\author{
В.М. Гунько \\ Институт химии поверхности им. А.А. Чуйко Национальной академии наук Украиньь \\ ул. Генерала Наумова, 17, Киев, 03164, Украина, vlad_gunko@ukr.net
}

Целью данного исследования был анализ разных методов, которые используются для морфологической и текстурной характеризации материалов, которые находятся в различных дисперсионных средах, а также явлений на границах раздела, которые являются основой данных методов. Есть несколько путей в аналогичных исследования: (i) адсорбиия-десорбция низкомолекулярных соединений (N2, $\mathrm{Ar}$ и т.д.); (ii) адсорбичия или пространственное ограничение в порах низко- и высокомолекулярных соединений при взаимодействии с твердыми частицами в жидкой среде; (іii) малоугловое рассеивание рентгеновских лучей или нейтронов; (iv) численньй анализ микроизображений ТЭМ, СЭМ и др.; (v) термопорометрия на основе дифференциальной сканирующей калориметрии с использованием термограмм плавления; (vi) криопорометрия на основе низкотемпературной ЯМР спектроскопии относительно зависимости интенсивности сигналов от температуры ниже температуры замерзания свободной жидкости; (vii) релаксометрия на основе ЯМР спектроскопии относительно температурной зависимости времени поперечной релаксации; и (viii) релаксометрии на основе зависимости тока термостимулированнгой деполяризации от температуры. Каждый из этих методов может характеризоваться определенными систематическими погрешностями. Однако параллельное использование нескольких методов позволяет установить причины и уровень систематических ошибок, что важно для корректной характеризации материалов, исследуемых в различных средах. Таким образом, чем больше методов используется в параллельных исследованиях, тем более надежной и полной может быть морфологическая и текстурная характеризация адсорбентов разной природы.

Ключевые слова: пирогенные оксиды, мезопористые кремнеземы, силикагель, активированный уголь, морфология частии, текстурные характеристики, систематические погрешности 


\section{REFERENCES}

1. Taylor J.R. An Introduction to Error Analysis: The Study of Uncertainties in Physical Measurements. 2nd Edition. (Sausalito, California: University Science Books, 1997).

2. Bevington P.R., Robinson D.K. Data Reduction and Error Analysis for the Physical Sciences. 2nd Edition. (Boston: WCB/McGraw-Hill, 1992).

3. Kirkup L. Experimental Methods. (John Wiley \& Sons Australia, Limited, 2002).

4. Baird D.C. Experimentation: An Introduction to Measurement Theory and Experiment Design. $3^{\text {rd }}$ ed. (Prentice Hall Englewood Cliffs, 1995).

5. Gregg S.J., Sing K.S.W. Adsorption, Surface Area and Porosity. $2^{\text {nd }}$ ed. (London: Academic Press, 1982).

6. Adamson A.W., Gast A.P. Physical Chemistry of Surface. $6^{\text {th }}$ edition. (New York: Wiley, 1997).

7. Iler R.K. The Chemistry of Silica. (Chichester: Wiley, 1979).

8. Legrand A.P. The Surface Properties of Silicas. (New York: Wiley, 1998).

9. Bergna H.E., Roberts W.O. Colloidal Silica: Fundamentals and Applications. (Boca Raton: CRC Press, 2006).

10. Tapia O., Bertrán J. (Eds.) Solvent Effects and Chemical Reactivity. (New York: Kluwer Academic Publishers, 2000).

11. Somasundaran P. (Ed.) Encyclopedia of Surface and Colloid Science. Third Edition. (Boca Raton: CRC Press, 2015).

12. Henderson M.A. Interaction of water with solid surfaces: fundamental aspects revisited. Surf. Sci. Report. 2002. 46(1-8): 1 .

13. Birdi K.S. (Ed.) Handbook of Surface and Colloid Chemistry. Third edition. (Boca Raton: CRC Press, 2009).

14. Al-Abadleh H.A., Grassian V.H. Oxide surfaces as environmental interfaces. Surf. Sci. Report. 2003. 52(3-4): 63.

15. Chandler D. Interfaces and the driving force of hydrophobic assembly. Nature. 2005. 437: 640.

16. Gun'ko V.M., Turov V.V. Nuclear Magnetic Resonance Studies of Interfacial Phenomena. (Boca Raton: CRC Press, 2013).

17. Gun'ko V.M. Composite materials: textural characteristics. Appl. Surf. Sci. 2014. 307: 444.

18. Gun'ko V.M., Turov V.V., Gorbik P.P. Water at the Interfaces. (Kyiv: Naukova Dumka, 2009).

19. Gun'ko V.M., Turov V.V., Zarko V.I., Goncharuk O.V., Pahklov E.M., Skubiszewska-Zięba J., Blitz J.P. Interfacial phenomena at a surface of individual and complex fumed nanooxides. Adv. Colloid Interface Sci. 2016. 235: 108 .

20. Gun'ko V.M. Interfacial phenomena: effects of confined space and structure of adsorbents on the behavior of polar and nonpolar adsorbates at low temperatures. Current Physical Chemistry. 2015. 5(2): 137.

21. Gun'ko V.M., Pakhlov E.M., Goncharuk O.V., Andriyko L.S., Nychiporuk Yu.M., Balakin D.Yu., Sternik D., Derylo-Marczewska A. Nanosilica modified by polydimethylsiloxane depolymerized and chemically bound to nanoparticles or physically bound to unmodified or modified surfaces: Structure and interfacial phenomena. J. Colloid Interface Sci. 2018. 529: 273.

22. Gun'ko V.M., Zarko V.I., Goncharuk O.V., Matkovsky A.K., Remez O.S., Skubiszewska-Zięba J., Wojcik G., Walusiak B., Blitz J.P. Nature and morphology of fumed oxides and features of interfacial phenomena. Appl. Surf. Sci. 2016. 366: 410.

23. Gun'ko V.M., Turov V.V., Krupska T.V., Pakhlov E.M. Behavior of water and methane bound to hydrophilic and hydrophobic nanosilicas and their mixture. Chem. Phys. Lett. 2017. 690: 25.

24. Turov V.V., Gun'ko V.M., Pakhlov E.M., Krupska T.V., Tsapko M.D., Charmas B., Kartel M.T. Influence of hydrophobic nanosilica and hydrophobic medium on water bound in hydrophilic components of complex systems. Colloids Surf. A. 2018. 552: 39.

25. Gun'ko V.M., Pakhlov E.M., Goncharuk O.V., Andriyko L.S., Marynin A.I., Ukrainets A.I., Charmas B., Skubiszewska-Zięba J., Blitz J.P. Influence of hydrophobization of fumed oxides on interactions with polar and nonpolar adsorbates. Appl. Surf. Sci. 2017. 423: 855.

26. Gun'ko V.M., Turov V.V., Pakhlov E.M., Krupska T.V., Charmas B. Effect of water content on the characteristics of hydro-compacted nanosilica. Appl. Surf. Sci. 2018. 459: 171.

27. Gun'ko V.M., Turov V.V., Turov A.V., Zarko V.I., Gerda V.I., Yanishpolskii V.V., Berezovska I.S., Tertykh V.A. Behaviour of pure water and water mixture with benzene or chloroform adsorbed onto ordered mesoporous silicas. Central European Journal of Chemistry. 2007. 5(2): 420.

28. Gun'ko V.M. Various methods to describe the morphological and textural characteristics of various materials. Him. Fiz. Tehnol. Poverhni. 2018. 9(4): 317.

29. Gun'ko V.M., Mikhalovsky S.V. Evaluation of slitlike porosity of carbon adsorbents. Carbon. 2004. $42(4): 843$.

30. Do D.D., Nguyen C., Do H.D. Characterization of micro-mesoporous carbon media. Colloids Surf. A. 2001. 187-188: 51. 
31. Platzer B., Maurer G. Application of a generalized Bender equation of state to the description of vapour-liquid in binary systems. Fluid Phase Equilibr. 1993. 84: 79.

32. Muniz W.B., Ramos F.M., de Campos Velho H.F. Entropy- and Tikhonov-based regularization techniques applied to the backwards heat equation. Comput. Math. Appl. 2000. 40(8-9): 1071.

33. Provencher S.W. A constrained regularization method for inverting data represented by linear algebraic or integral equations. Comput. Phys. Commun. 1982. 27(3): 213.

34. Gun'ko V.M., Voronin E.F., Nosach L.V., Turov V.V., Wang Z., Vasilenko A.P., Leboda R., SkubiszewskaZięba J., Janusz W., Mikhalovsky S.V. Structural, textural and adsorption characteristics of nanosilica mechanochemically activated in different media. J. Colloid Interface Sci. 2011. 355(2): 300.

35. Gun'ko V.M., Leboda R., Skubiszewska-Zięba J., Gawdzik B., Charmas B. Structural characteristics of porous polymers treated by freezing with water or acetone. Appl. Surf. Sci. 2005. 252(3): 612.

36. Pujari P.K., Sen D., Amarendra G., Abhaya S., Pandey A.K., Dutta D., Mazumder S. Study of pore structure in grafted polymer membranes using slow positron beam and small-angle X-ray scattering techniques. Nucl. Instrum. Methods Phys. Res., Sect. B. 2007. 254(2): 278.

37. Sternik D., Galaburda M., Bogatyrov V.M., Gun'ko V.M. Influence of the synthesis method on the structural characteristics of novel hybrid adsorbents based on bentonite. Colloids Interfaces. 2019. 3(1): 18.

38. Gun'ko V.M., Meikle S.T., Kozynchenko O.P., Tennison S.R., Ehrburger-Dolle F., Morfin I., Mikhalovsky S.V. Comparative characterization of carbon and polymer adsorbents by SAXS and nitrogen adsorption methods. J. Phys. Chem. C. 2011. 115(21): 10727.

39. Sakurai S. SAXS evaluation of size distribution for nanoparticles. Chapter 5 (http://dx.doi.org/10.5772/105981), In A.E. Ares (ed.), X-ray Scattering, (DOI: 10.5772/65049), (Croatia: InTech, 2017). P. 107-134.

40. Brumberger H. (Ed.) Small Angle X-ray Scattering. (New York, Syracuse: Gordon \& Breach, 1965).

41. Dieudonné Ph., Hafidi A.A., Delord P., Phalippou J. Transformation of nanostructure of silica gels during drying. J. Non-Crystal. Solids. 2000. 262(1-3): 155.

42. Fairén-Jiménez D., Carrasco-Marín F., Djurado D., Bley F., Ehrburger-Dolle F., Moreno-Castilla C. Surface area and microporosity of carbon aerogels from gas adsorption and small- and wide-angle X-ray scattering measurements. J. Phys. Chem. B. 2006. 110(17): 8681.

43. Gun'ko V.M., Turov V.V., Pakhlov E.M., Krupska T.V., Charmas B. Effect of water content on the characteristics of hydro-compacted nanosilica. Appl. Surf. Sci. 2018. 459: 171.

44. Goliszek M., Podkościelna B., Fila K., Riazanova A.V., Aminzadeh S., Sevastyanova O., Gun'ko V.M. Synthesis and structure characterization of polymeric nanoporous microspheres with lignin. Cellulose. 2018. 25(10): 5843.

45. Gun'ko V.M., Turov V.V., Pakhlov E.M., Krupska T.V., Borysenko M.V., Kartel M.T., Charmas B. Water interactions with hydrophobic versus hydrophilic nanosilica. Langmuir. 2018. 34(40): 12145.

46. ImageJ. 2019. https://imagej.nih.gov/ij/, https://imagej.nih.gov/ij/plugins/granulometry.html.

47. Fiji. 2019. https://fiji.sc/, https://imagej.net/Local_Thickness.

48. Gun'ko V.M., Savina I.N., Mikhalovsky S.V. Cryogels: Morphological, structural and adsorption characterization. Adv. Colloid Interface Sci. 2013. 187-188: 1.

49. Gun'ko V.M., Zarko V.I., Leboda R., Chibowski E. Aqueous suspensions of fumed oxides: particle size distribution and zeta potential. Adv. Colloid Interface Sci. 2001. 91(1): 1.

50. Gun'ko V.M., Klyueva A.V., Levchuk Yu.N., Leboda R. Photon correlation spectroscopy investigations of proteins. Adv. Colloid Interface Sci. 2003. 105(1-3): 201.

51. Hunter R.J. Introduction to Modern Colloid Science. (London: Oxford University Press, 1993).

52. Mitchell J., Webber J.B.W., Strange J.H. Nuclear magnetic resonance cryoporometry. Phys. Rep. 2008. 461(1): 1.

53. Petrov O.V., Furó I. NMR cryoporometry: Principles, applications and potential. Progr. NMR Spectroscopy. 2009. 54(2): 97.

54. Aksnes D.W., Forl K., Kimtys L. Pore size distribution in mesoporous materials as studied by 1 H NMR. Phys. Chem. Chem. Phys. 2001. 3(15): 3203.

55. Hay J.N., Laity P.R. Observations of water migration during thermoporometry studies of cellulose films. Polymer. 2000. 41(16): 6171.

56. Landry M.R. Thermoporometry by differential scanning calorimetry: experimental considerations and applications. Thermochim. Acta. 2005. 433(1-2): 27.

57. Weber J., Bergström L. Mesoporous hydrogels: revealing reversible porosity by cryoporometry, X-ray scattering, and gas adsorption. Langmuir. 2010. 26(12): 10158.

58. Rohman G., Lauprêtre F., Boileau S., Guérin P., Grande D. Poly(D,L-lactide)/poly(methyl methacrylate) interpenetrating polymer networks: synthesis, characterization, and use as precursors to porous polymeric materials. Polymer. 2007. 48(24): 7017. 
59. Turov V.V., Gun'ko V.M., Zarko V.I., Goncharuk O.V., Krupska T.V., Turov A.V., Leboda R., SkubiszewskaZięba J. Interfacial behavior of n-decane bound to weakly hydrated silica gel and nanosilica over a broad temperature range. Langmuir. 2013. 29(13): 4303.

60. Gun'ko V.M., Turov V.V., Zarko V.I., Pakhlov E.M., Charmas B., Skubiszewska-Zięba J. Influence of structural organization of silicas on interfacial phenomena. Colloids Surf. A. 2016. 492: 230.

61. Gun'ko V.M., Goncharuk O.V., Goworek J. Evaporation of polar and nonpolar liquids from silica gels and fumed silica. Colloids Surf. A. 2015. 474: 52.

62. Gun'ko V.M., Zarko V.I., Goncharuk E.V., Andriyko L.S., Turov V.V., Nychiporuk Y.M., Leboda R., Skubiszewska-Zięba J., Gabchak A.L., Osovskii V.D., Ptushinskii Y.G., Yurchenko G.R., Mishchuk O.A., Gorbyk P.P., Pissis P., Blitz J.P. TSDC spectroscopy of relaxational and interfacial phenomena. Adv. Colloid Interface Sci. 2007. 131(1-2): 1.

Received 23.10.2019, accepted 14.02.2020 